\title{
7 $\alpha$-Hydroxypregnenolone, a new key regulator of locomotor activity of vertebrates: identification, mode of action, and functional significance
}

\author{
Kazuyoshi Tsutsui ${ }^{1}$, Shogo Haraguchi ${ }^{1}$, Masahiro Matsunaga ${ }^{2}$, Kazuhiko Inoue ${ }^{1,2}$ and Hubert Vaudry ${ }^{3}$ \\ 1 Laboratory of Integrative Brain Sciences, Department of Biology, Waseda University and Center for Medical Life Science of Waseda University, Tokyo, Japan \\ 2 Laboratory of Brain Science, Faculty of Integrated Arts and Sciences, Hiroshima University, Higashi-Hiroshima, Japan \\ ${ }^{3}$ Laboratory of Neuronal and Neuroendocrine Differentiation and Communication (INSERM U982), European Institute for Peptide Research, University of Rouen, \\ Mont-Saint-Aignan, France
}

\section{Edited by:}

Eric W. Roubos, Radboud University Nijmegen, Netherlands

Reviewed by:

Barney A. Schlinger, University of California at Los Angeles, USA

Robert Dores, University of Minnesota, USA

Olivier Kah, CNRS UMR 6026, France

\section{*Correspondence:}

Kazuyoshi Tsutsui, Laboratory of Integrative Brain Sciences, Department of Biology, Waseda University and Center for Medical Life Science of Waseda University, 2-2 Wakamatsucho, Shinjuku-ku, Tokyo 162-8480,

Japan.

e-mail: k-tsutsui@waseda.jp
Steroids synthesized de novo by the central and peripheral nervous systems are called neurosteroids. The formation of neurosteroids from cholesterol in the brain was originally demonstrated in mammals by Baulieu and colleagues. Our studies over the past two decades have also shown that, in birds and amphibians as in mammals, the brain expresses several kinds of steroidogenic enzymes and produces a variety of neurosteroids. Thus, de novo neurosteroidogenesis from cholesterol is a conserved property that occurs throughout vertebrates. However, the biosynthetic pathways of neurosteroids in the brain of vertebrates was considered to be still incompletely elucidated. Recently, $7 \alpha$-hydroxypregnenolone was identified as a novel bioactive neurosteroid stimulating locomotor activity in the brain of newts and quail through activation of the dopaminergic system. Subsequently, diurnal and seasonal changes in synthesis of $7 \alpha$-hydroxypregnenolone in the brain were demonstrated. Interestingly, melatonin derived from the pineal gland and eyes regulates $7 \alpha$-hydroxypregnenolone synthesis in the brain, thus inducing diurnal locomotor changes. Prolactin, an adenohypophyseal hormone, regulates $7 \alpha$-hydroxypregnenolone synthesis in the brain, and may also induce seasonal locomotor changes. This review highlights the identification, mode of action, and functional significance of $7 \alpha$-hydroxypregnenolone, a new key regulator of locomotor activity of vertebrates, in terms of diurnal and seasonal changes in $7 \alpha$-hydroxypregnenolone synthesis, and describes some of their regulatory mechanisms.

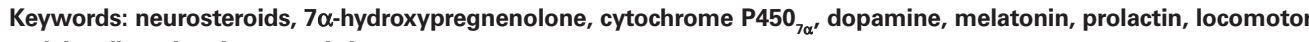
activity, diurnal and seasonal changes

\section{INTRODUCTION}

The brain has traditionally been considered as a target site for peripheral steroid hormones. In addition to this classical concept, new findings over the past two decades have shown that the brain has the capacity to synthesize steroids de novo from cholesterol, the so-called "neurosteroids" (for reviews, see Baulieu, 1997; Tsutsui et al., 1999, 2000, 2003, 2006; Compagnone and Mellon, 2000; Mellon and Vaudry, 2001; Tsutsui and Mellon, 2006; Do-Rego et al., 2009a). Brain neurosteroid contents are not affected by removal of peripheral steroid hormones following adrenalectomy, castration, and/or hypophysectomy (Corpéchot et al., 1981, 1983; Tsutsui and Yamazaki, 1995; Mensah-Nyagan et al., 1996a) and diurnal and seasonal changes in neurosteroid contents are evident in the brain (Takase et al., 1999; Matsunaga et al., 2004; Tsutsui et al., 2008; Haraguchi et al., 2010).

The formation of neurosteroids in the brain was originally demonstrated in mammals by Baulieu and colleagues (Corpéchot et al., 1981, 1983; Robel and Baulieu, 1985; Lanthier and Patwardhan, 1986; Robel et al., 1987; Jo et al., 1989; Mathur et al., 1993; Mellon and Deschepper, 1993; Compagnone et al., 1995). In non-mammalian vertebrates, i.e., in birds, amphibians, and fish, the brain expresses several kinds of steroidogenic enzymes and produces a variety of neurosteroids (for reviews, see Tsutsui et al., 1999, 2000, 2003, 2006; Mellon and Vaudry, 2001; Tsutsui and Mellon, 2006; Do-Rego et al., 2009a). Birds have always served as excellent animal models for understanding the actions of steroids on brain and behavior, and studies investigating neurosteroid synthesis and action in birds may be of general significance in vertebrates. We therefore analyzed neurosteroids formed from cholesterol in the avian brain using the Japanese quail Coturnix japonica (Tsutsui and Yamazaki, 1995; Usui et al., 1995; Tsutsui et al., 1997, 1999, 2003; Ukena et al., 1999, 2001; Matsunaga et al., 2001, 2002; Tsutsui and Schlinger, 2001). Schlinger and colleagues undertook similar studies in passeriform bird species (Vanson et al., 1996; Schlinger et al., 1999; Freking et al., 2000; Soma et al., 2004). The formation of several neurosteroids from cholesterol is now also well documented in amphibians (Mensah-Nyagan et al., 1994, 1996a,b, 1999; Beaujean et al., 1999; Takase et al., 1999, 2002; Inai et al., 2003; Matsunaga et al., 2004; Do-Rego et al., 2007; Bruzzone et al., 2010) and fish (Sakamoto et al., 2001). Accordingly, de novo neurosteroidogenesis in the brain from cholesterol appears to be a conserved property across vertebrates (for reviews, see Baulieu, 1997; Tsutsui et al., 1999, 2000, 2003, 2006; Compagnone and Mellon, 2000; Mellon and Vaudry, 2001; Tsutsui and Mellon, 
2006; Do-Rego et al., 2009a). However, the biosynthetic pathways leading to the formation of neurosteroids in vertebrates was not fully characterized (for a review, see Tsutsui et al., 2006).

In fact, we recently found that the newt brain actively produces $7 \alpha$-hydroxypregnenolone, a previously undescribed amphibian neurosteroid, from pregnenolone (Matsunaga et al., 2004). Interestingly, $7 \alpha$-hydroxypregnenolone acts as a novel neuronal modulator to stimulate locomotor activity of newts (Matsunaga et al., 2004). We also identified $7 \alpha$ - and $7 \beta$-hydroxypregnenolone in quail brain by using biochemical techniques (Tsutsui et al., 2008). It was subsequently shown that $7 \alpha$-hydroxypregnenolone, but not $7 \beta$-hydroxypregnenolone, stimulates locomotor activity in quail (Tsutsui et al., 2008). Finally, we found that cytochrome P450 ${ }_{7 \alpha}$ catalyzes the conversion of pregnenolone to $7 \alpha$-hydroxypregnenolone in the brain of these vertebrates (Tsutsui et al., 2008; Haraguchi et al., 2010).

This review describes the discovery of $7 \alpha$-hydroxypregnenolone, a new key regulator of locomotor activity in vertebrates, the mode of action, and the functional significance of this neurosteroid. This review also summarizes the current knowledge regarding the diurnal and seasonal changes in $7 \alpha$-hydroxypregnenolone synthesis, and their regulatory mechanisms.

\section{OVERVIEW OF NEUROSTEROIDOGENESIS IN THE BRAIN}

It has long been established that the central nervous system is a target site for steroid hormone action. More recently, several laboratories have established unequivocally that the brain has the ability to synthesize neurosteroids from cholesterol. The new concept that neurosteroids could be formed de novo in the brain of mammals was first put forward by Baulieu and colleagues (for a review, see Baulieu, 1997). These researchers found high concentrations of several steroids, such as pregnenolone, dehydroepiandrosterone, and their sulfate and lipoidal esters, in the brain of several mammalian species (Corpéchot et al., 1981, 1983; Robel and Baulieu, 1985; Lanthier and Patwardhan, 1986; Robel et al., 1986, 1987; Jo et al., 1989; Mathur et al., 1993). They also showed that the brain content of these steroids remains constant even after removal of peripheral steroids by adrenalectomy, castration, and/or hypophysectomy. These observations revealed that the brain of mammals can synthesize neurosteroids de novo from cholesterol (Corpéchot et al., 1981, 1983; Robel and Baulieu, 1985; Robel et al., 1986, 1987; Jo et al., 1989). Following this pioneering discovery in the brain of mammals (for a review, see Baulieu, 1997), the concept of de novo neurosteroidogenesis from cholesterol was extended to the brain of birds (Tsutsui and Yamazaki, 1995; Usui et al., 1995; Vanson et al., 1996; Tsutsui et al., 1997, 1999, 2003; Schlinger et al., 1999; Ukena et al., 1999, 2001; Freking et al., 2000; Lea et al., 2001; Matsunaga et al., 2001, 2002; Tsutsui and Schlinger, 2001; Soma et al., 2004), and amphibians (Mensah-Nyagan et al., 1994, 1996a,b, 1999; Beaujean et al., 1999; Takase et al., 1999, 2002; Inai et al., 2003; Matsunaga et al., 2004; Do-Rego et al., 2007; Bruzzone et al., 2010).

In peripheral organs, including the gonads, adrenals, and placenta, pregnenolone is the common precursor of all steroid hormones. The formation of pregnenolone is initiated by cleavage of the cholesterol side-chain by cytochrome P450scc, a rate-limiting mitochondrial enzyme (Figure 1). As an initial step in the demonstration of pregnenolone biosynthesis in the brain of birds, Tsutsui and Yamazaki (1995) showed that the concentration of pregnenolone in the quail brain is higher than in the plasma. The accumulation of pregnenolone in the quail brain was largely independent of peripheral steroidogenic organs since a high level of brain pregnenolone persists in hypophysectomized birds (Tsutsui and Yamazaki, 1995). The formation of pregnenolone from cholesterol was found to occur in quail brain mitochondria, and Western immunoblot analysis with an antibody against purified bovine P450scc confirmed the presence of the P450scc protein in quail

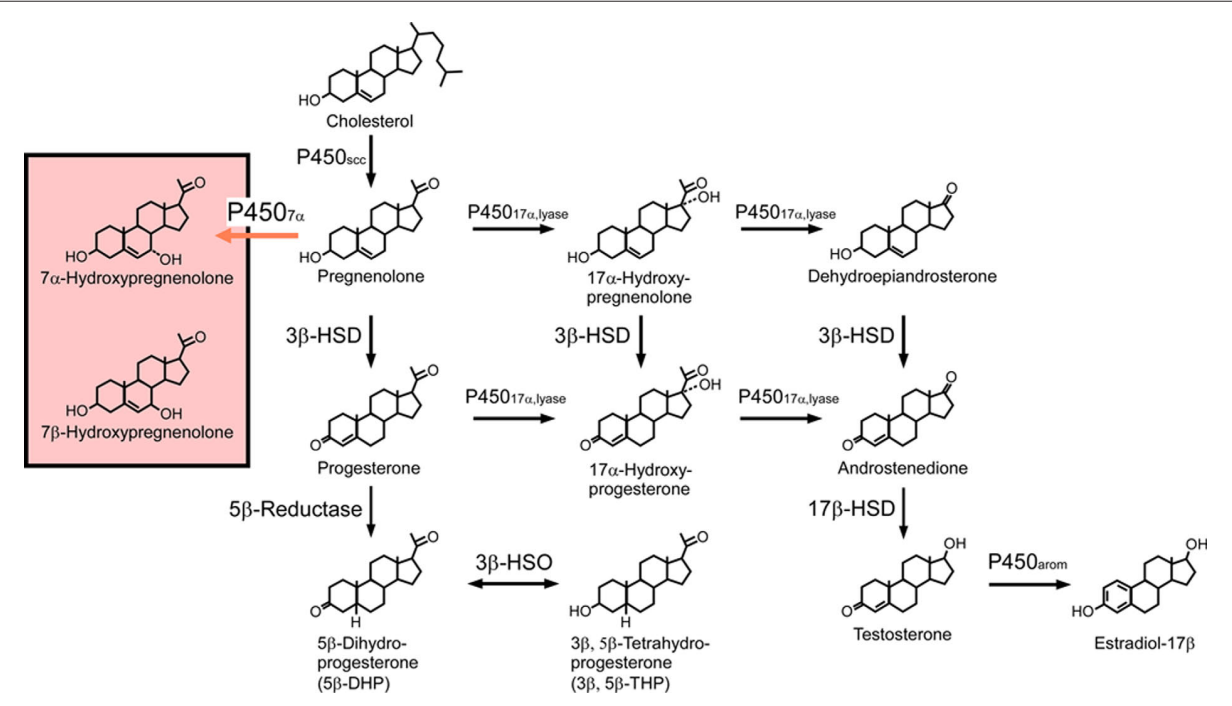

FIGURE 1 | Biosynthetic pathways for neurosteroids in the quail brain. The black arrows indicate the biosynthetic pathways of neurosteroids identified previously in the quail brain. The red arrow indicates a newly identified biosynthetic pathway resulting in the biosynthesis of
$7 \alpha$-hydroxypregnenolone. Although the quail brain possesses both $7 \alpha$-and $7 \beta$-hydroxypregnenolone, it is still unclear whether $\mathrm{P} 450_{7 \alpha}$ can also convert pregnenolone to $7 \beta$-hydroxypregnenolone. See the text for details. 
brain homogenates (Tsutsui and Yamazaki, 1995). Similar findings were reported in the ring dove (Tsutsui et al., 1999; Lea et al., 2001) and zebra finch (Freking et al., 2000). Taken together, these data indicate that, in birds, the brain contains cytochrome P450scc and synthesizes pregnenolone from cholesterol (for reviews, see Tsutsui et al., 1997, 1999, 2003, 2006; Tsutsui and Schlinger, 2001) as previously shown is mammals (Corpéchot et al., 1981, 1983; Robel and Baulieu, 1985; Lanthier and Patwardhan, 1986; Robel et al., 1986, 1987; Hu et al., 1987; Le Goascogne et al., 1987; Jo et al., 1989; Jung-Testas et al., 1989; Baulieu and Robel, 1990; Iwahashi et al., 1990; Baulieu, 1991; Papadopoulos et al., 1992; Mathur et al., 1993; Mellon and Deschepper, 1993; Compagnone et al., 1995; Kohchi et al., 1998; Ukena et al., 1998).

In the brain of birds, pregnenolone is metabolized to progesterone by $3 \beta$-hydroxysteroid dehydrogenase $/ \Delta^{5}-\Delta^{4}$-isomerase (3ß-HSD; Figure 1). By using biochemical techniques combined with high-performance liquid chromatography (HPLC) analysis, we have demonstrated that, in the quail brain, pregnenolone is converted to progesterone (Ukena et al., 1999). The biosynthesis of progesterone increased with time and is completely abolished by trilostane, a specific inhibitor of 33-HSD (Ukena et al., 1999). The expression of $3 \beta$-HSD mRNA in the quail brain was revealed by using RT-PCR analysis together with Southern hybridization (Ukena et al., 1999). Similar observations were reported in the brains of zebra finches (Vanson et al., 1996) and ring doves (Lea et al., 2001). The expression of both $3 \beta$-HSD protein and its mRNA has also been observed in the brain of mammals (Dupont et al., 1994; Guennoun et al., 1995; Sanne and Krueger, 1995; Kohchi et al., 1998; Ukena et al., 1999). In addition, 3 $\beta$-HSD activity has been demonstrated biochemically in the brain of mammals (Weidenfeld et al., 1980; Akwa et al., 1993; Kabbadj et al., 1993; Ukena et al., 1999).

Progesterone is further metabolized via $5 \beta$ reduction to several derivatives including $5 \beta$-dihydroprogesterone (5 3 -DHP) and $3 \beta, 5 \beta$-tetrahydroprogesterone ( $3 \beta, 5 \beta$-THP; Figure 1). Both $5 \beta$-DHP (Ukena et al., 2001) and $3 \beta, 5 \beta$-THP (Tsutsui et al., 2003) have been shown to occur in the quail brain. In birds, $5 \beta$-reduction also represents a route of androgen metabolism in the brain (Massa and Sharp, 1981; Schlinger and Callard, 1987). In contrast to birds, in mammals, progesterone is converted to $5 \alpha$-DHP and $3 \alpha, 5 \alpha$-THP due to the presence of $5 \alpha$-reductase and $3 \alpha$-HSD (for reviews, see Baulieu, 1997; Compagnone and Mellon, 2000). Another route of progesterone metabolism is mediated by $17 \alpha$-hydroxylase/c17,20-lyase (cytochrome $\mathrm{P}_{45} 0_{17 \alpha, \text { lyase }}$ ) which, in addition to converting pregnenolone to dehydroepiandrosterone via $17 \alpha$-hydroxypregnenolone, also converts progesterone to androstenedione via $17 \alpha$-hydroxyprogesterone (Figure 1). Both of these metabolic pathways have been demonstrated in the quail brain using biochemical techniques combined with HPLC analysis, and by RT-PCR analysis of cytochrome P450 ${ }_{17 \alpha, 1 y a s e}$ mRNA (Matsunaga et al., 2001, 2002). The expression of ${\mathrm{P} 450_{17 \alpha} \text {,lyase }}_{\text {, }}$ has also been detected in the brain of mammals (Compagnone et al., 1995; Strömstedt and Waterman, 1995; Kohchi et al., 1998).

The avian brain has also been shown to contain $17 \beta$ hydroxysteroid dehydrogenase (17 $\beta$-HSD) that is needed to convert androstenedione to testosterone, and cytochrome P450arom, which converts testosterone to estradiol-17 $\beta$ (Figure 1). The expression and localization of $17 \beta$-HSD in the quail brain was demonstrated by Matsunaga et al. (2002) while other studies revealed the expression and localization of cytochrome P450arom (Schlinger and Callard, 1987, 1989a,b, 1991; Balthazart et al., 1990a,b, 1991). Therefore, not only androgens but also estrogens may be synthesized directly in the avian brain.

There is also now clear evidence that the brain of amphibians has the capability of synthesizing neurosteroids and the presence of steroidogenic enzymes has been documented in the brain of both anurans (frogs) and urodeles (newts; for reviews, see MensahNyagan et al., 1999; Tsutsui et al., 1999, 2000, 2009b, 2010; Mellon and Vaudry, 2001; Do-Rego et al., 2009a,b). In Xenopus laevis, Takase et al. (1999) have reported that the concentrations of pregnenolone, the main precursor of neurosteroids, and its sulfate ester are higher in the brain than in the gonad and plasma (Takase et al., 1999). In the European green frog Rana ridibunda, incubation of brain slices with tritiated pregnenolone combined with HPLC analysis of the incubation medium has shown that androgens, estrogens, and adrenal steroids are generated from pregnenolone de novo (MensahNyagan et al., 1994, 1996a,b). Concurrently, immunohistochemical studies revealed the presence of various steroidogenic enzymes in the brain of Rana species, such as cytochrome P450scc (Takase et al., 1999), 3ß-HSD (Mensah-Nyagan et al., 1994), cytochrome

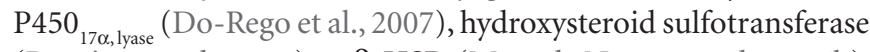
(Beaujean et al., 1999), 17ß-HSD (Mensah-Nyagan et al., 1996b), and $5 \alpha$-reductase (Bruzzone et al., 2010). Takase et al. (1999) have also reported that the brain of $R$. nigromaculata also expresses mRNA encoding cytochrome $\mathrm{P} 450_{11 \beta \text {,aldo }}$ that catalyzes the final step of biosynthesis of the adrenal steroids, corticosterone, and aldosterone (Takase et al., 2002). In urodeles, Inai et al. (2003) and Takase et al. (2010) have found that the brain of the newt Cynops pyrrhogaster expresses cytochrome P450scc and produces pregnenolone from cholesterol. In this species, the tissue concentration of pregnenolone was higher in the brain than in peripheral steroidogenic organs. Inai et al. (2003) have found that the newt brain also expresses $3 \beta$-HSD and produces progesterone from pregnenolone. It thus appears that biosynthesis of neurosteroids occurs in the brain of both anuran and urodele species.

\section{IDENTIFICATION OF 7 $\alpha$-HYDROXYPREGNENOLONE IN THE BRAIN}

We initially found that the brain of the newt C. pyrrhogaster actively produces an unknown neurosteroid from pregnenolone. It appeared that the concentration of this compound is greater than those of any neurosteroids identified previously in amphibians, suggesting that this unknown neurosteroid could be involved in key neurophysiological functions. Therefore, we sought to identify this amphibian neurosteroid from the newt brain by using biochemical and analytical techniques (Matsunaga et al., 2004). Incubation of newt brain homogenates with tritiated pregnenolone combined with HPLC analysis of the incubation medium has shown that a major radioactive peak is detected before pregnenolone elution (Matsunaga et al., 2004). Using several non-radioactive steroids as reference standards for HPLC analysis, Matsunaga et al. (2004) have indicated that $7 \alpha$ - and $7 \beta$-hydroxypregnenolone exhibit the same retention time as the radioactive peak. The radioactive HPLC peak corresponding to 
$7 \alpha$ - and $7 \beta$-hydroxypregnenolone increased in a time-dependent manner, and the inhibitor of cytochrome P450s, ketoconazole, reduced the production of the metabolite (Matsunaga et al., 2004). This HPLC peak was collected and subjected to thin-layer chromatography (TLC; Matsunaga et al., 2004). Only $7 \alpha$-hydroxypregnenolone had the same retention position as the radioactive metabolite of pregnenolone under identical chromatographic conditions (Matsunaga et al., 2004). The pregnenolone metabolite was further analyzed by gas chromatography-mass spectrometry (GC-MS). Trimethylsilyl ether derivatives of the authentic $7 \alpha$ - and $7 \beta$-hydroxypregnenolone and the metabolite obtained from non-radioactive pregnenolone were prepared and subsequently applied to GC-MS analysis (Matsunaga et al., 2004). Although $7 \alpha$ - and $7 \beta$-hydroxypregnenolone had the same mass spectrum, their retention times were different in GC-MS. Based on GC-MS, $7 \alpha$-hydroxypregnenolone and the metabolite had an identical retention time and the same diagnostically important ions. Thus, we could identify the unknown neurosteroid converted from pregnenolone in the newt brain as $7 \alpha$-hydroxypregnenolone (Matsunaga et al., 2004).

Subsequently, we found $7 \alpha$ - and $7 \beta$-hydroxypregnenolone in the quail brain by using the same biochemical techniques (Tsutsui et al., 2008). Quail brain homogenates were incubated with tritiated pregnenolone, and radioactive metabolites were analyzed by reversed-phase HPLC (Tsutsui et al., 2008). A major radioactive peak of the metabolites was collected and subjected to TLC (Tsutsui et al., 2008). Quail brain homogenates produced two radioactive metabolites from ${ }^{3} \mathrm{H}$-pregnenolone that exhibit the same retention times as the $7 \alpha$ - and $7 \beta$-hydroxypregnenolone standards. The metabolites of pregnenolone were further analyzed by GC-MS (Tsutsui et al., 2008). The metabolites had retention times that are identical to $7 \alpha$ - and $7 \beta$-hydroxypregnenolone. The unknown avian neurosteroids formed from pregnenolone in the quail brain were thus identified as $7 \alpha$ - and $7 \beta$-hydroxypregnenolone (Figure 1; Tsutsui et al., 2008).

\section{IDENTIFICATION OF CYTOCHROME P450 PRODUCING $7 \alpha$-HYDROXYPREGNENOLONE IN THE BRAIN}

$7 \alpha$-Hydroxypregnenolone is synthesized from pregnenolone through the enzymatic activity of cytochrome $\mathrm{P} 450_{7 \alpha}$ (Figures 1 and 2 ). In order to prove that $7 \alpha$-hydroxypregnenolone is synthesized in the brain, it is therefore necessary to show that the brain expresses $\mathrm{P}_{450_{7 \alpha}}$. A full length, $2341 \mathrm{bp}$ cDNA prepared from quail brain tissue was identified as encoding a putative cytochrome $\mathrm{P} 450_{7 \alpha}$ (Tsutsui et al., 2008). The putative quail $\mathrm{P} 50_{7 \alpha}$ open reading frame was initiated with a methionine at

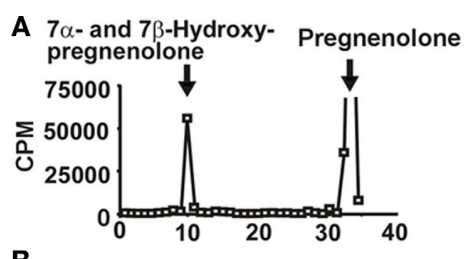

B

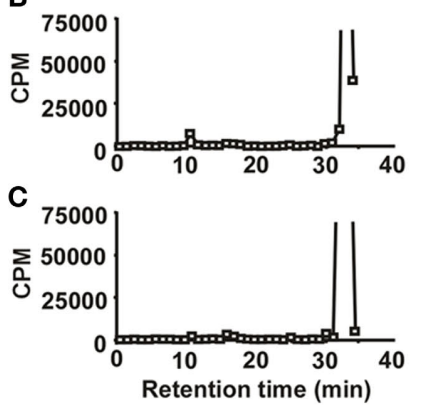

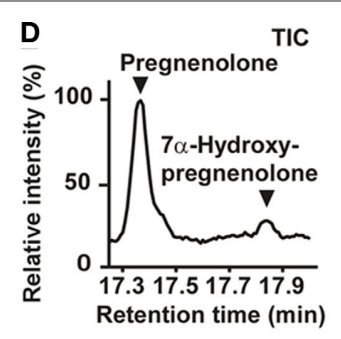

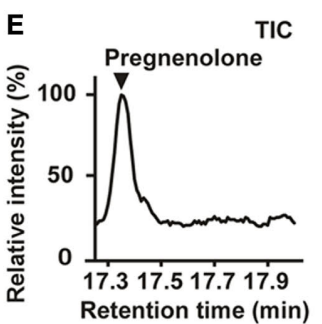

$\mathbf{F}$

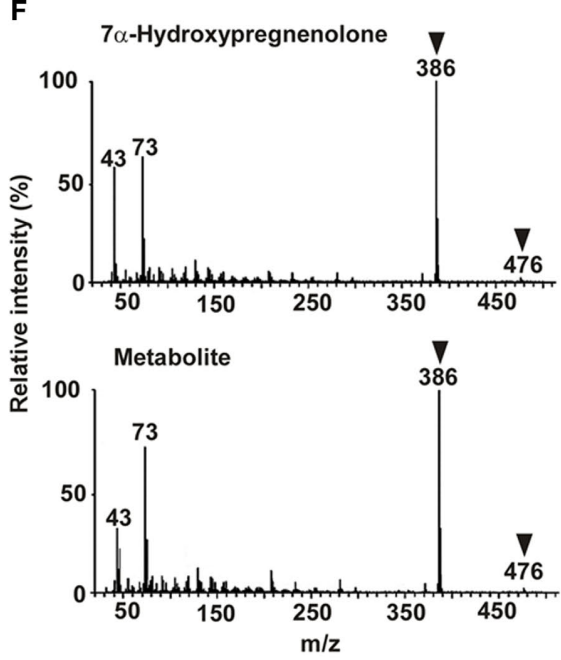

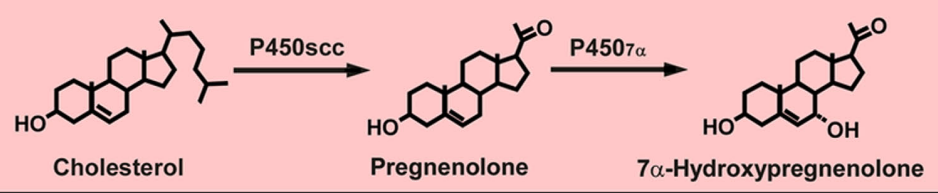

FIGURE 2 | $7 \alpha$-Hydroxypregnenolone synthesis in COS-7 cells expressing quail $\mathbf{P 4 5 0}_{7 \alpha^{*}}$ (A) HPLC profile of $7 \alpha$ - and/or $7 \beta$-hydroxypregnenolone and pregnenolone extracted from COS-7 cells that were transfected with quail $\mathrm{P} 4 \mathrm{O}_{7 \alpha} \mathrm{cDNA}$ and incubated with ${ }^{3} \mathrm{H}$-pregnenolone. The ordinate indicates the radioactivity measured in each HPLC fraction, and the arrows indicate the elution positions of standard steroids, i.e., pregnenolone and $7 \alpha$ - and/or 73-hydroxypregnenolone. (B) HPLC profile of the extract from COS-7 cells that were transfected with quail $\mathrm{P}_{45} \mathrm{O}_{7 \alpha} \mathrm{CDNA}$ and incubated with ${ }^{3} \mathrm{H}-$ pregnenolone in the presence of $10^{-4} \mathrm{M}$ ketoconazole, an inhibitor of $\mathrm{P} 450 \mathrm{~s}$. (C) HPLC profile of the extract from non-transfected COS-7 cells incubated with ${ }^{3} \mathrm{H}$-pregnenolone. (D) GC-MS analysis of $7 \alpha$-hydroxypregnenolone. GC-MS total-ion current (TIC) trace of the extract from COS-7 cells that were transfected with quail $\mathrm{P}_{5} 50_{7 \alpha} \mathrm{CDNA}$ and incubated with $10^{-7} \mathrm{M}$ pregnenolone. The arrowheads show the peaks corresponding to $7 \alpha-$ hydroxypregnenolone and pregnenolone. (E) GC-MSTIC trace of the extract from non-transfected COS-7 cells. (F) GC-MS of trimethylsilyl ether derivatives of an unknown pregnenolone metabolite and authentic $7 \alpha$-hydroxypregnenolone. The arrowheads indicate diagnostically important ions of $7 \alpha$-hydroxypregnenolone ( $\mathrm{m} / \mathrm{z} 386$ and 476). Adapted from Tsutsui et al. (2008). 
nucleotide 72 and terminates with a TGA codon at nucleotide 1581, encoding a protein of 503 amino acids. The enzymatic activity of this putative quail $\mathrm{P}^{4} 50_{7 \alpha}$ was demonstrated in homogenates of COS-7 cells transfected with the putative quail $\mathrm{P}_{50} 0_{70}$ cDNA (Figure 2; Tsutsui et al., 2008). As demonstrated by HPLC analyses, the homogenate converted pregnenolone to $7 \alpha$ - and/or $7 \beta$-hydroxypregnenolone (Figure 2A), and ketoconazole partially inhibited this conversion (Figure 2B). Pregnenolone was not converted to $7 \alpha$ - and/or $7 \beta$-hydroxypregnenolone in COS-7 cells without transfection of quail P450 $0_{7 \alpha}$ CDNA (Figure 2C). Subsequently, $7 \alpha$-hydroxypregnenolone but not $7 \beta$-hydroxypregnenolone synthesis was confirmed by GC-MS (Figures 2D-F; Tsutsui et al., 2008). Although it is still unclear whether $\mathrm{P}_{450_{7 \alpha}}$ can also convert pregnenolone to $7 \beta$-hydroxypregnenolone, the presence of $7 \beta$-hydroxypregnenolone as well as $7 \alpha$-hydroxypregnenolone is evident in the quail brain (Figure 1; Tsutsui et al., 2008). The production of $7 \alpha$-hydroxypregnenolone in the brain may be a conserved property of vertebrates, because this neurosteroid has also been identified in the brains of newts (Matsunaga et al., 2004) and mammals (Akwa et al., 1992; Doostzadeh and Morfin, 1997; WeillEngerer et al., 2003; Yau et al., 2003).

Subsequently, a cDNA encoding a putative cytochrome $\mathrm{P} 450_{7 \alpha}$ was identified from newt brain tissue (Haraguchi et al., 2010). The newt P450 ${ }_{7 \alpha}$ cDNA had a full length of $2598 \mathrm{bp}$. The open reading frame commenced with a methionine at nucleotide 157 and terminates with a TAG codon at nucleotide 1681, encoding a protein of 508 amino acids. The enzymatic activity of this putative newt $\mathrm{P} 450_{7 \alpha}$ was then demonstrated (Haraguchi et al., 2010). The homogenate of COS-7 cells transfected with the putative newt P450 $0_{7 \alpha}$ cDNA converted pregnenolone into $7 \alpha$-hydroxypregnenolone as shown by HPLC analysis, and ketoconazole abolished this metabolic process. COS-7 cells without transfection of newt $\mathrm{P} 450_{7 \alpha}$ cDNA did not convert pregnenolone into $7 \alpha$-hydroxypregnenolone. $7 \alpha$-Hydroxypregnenolone synthesis was further confirmed by GC-MS analysis (Haraguchi et al., 2010).

\section{BIOLOGICAL ACTION OF $7 \alpha$-HYDROXYPREGNENOLONE ON LOCOMOTOR ACTIVITY}

Because $7 \alpha$-hydroxypregnenolone is actively produced in the brain of the newt C. pyrrhogaster, this seasonally breeding amphibian has served as a suitable animal model to investigate the biological action of $7 \alpha$-hydroxypregnenolone. The production of $7 \alpha$-hydroxypregnenolone in the diencephalon and rhombencephalon of male newts was much higher than in the telencephalon and peripheral steroidogenic glands (Matsunaga et al., 2004). In addition, $7 \alpha$-hydroxypregnenolone synthesis in the brain of male newts showed marked changes during the annual breeding cycle, with a maximum level in the spring breeding period when locomotor activity of wild populations of the same species increases (Matsunaga et al., 2004; see Seasonal Changes in $7 \alpha$-Hydroxypregnenolone Synthesis and Locomotor Activity and their Regulatory Mechanisms for further discussion). We therefore analyzed the effect of $7 \alpha$-hydroxypregnenolone on locomotor activity (Matsunaga et al., 2004).

Behavioral analysis demonstrated that administration of $7 \alpha$-hydroxypregnenolone acutely increases locomotor activity of male newts in the non-breeding period when endogenous
$7 \alpha$-hydroxypregnenolone synthesis in the brain is low (Figure 3; Matsunaga et al., 2004). This stimulatory effect occurred in a dose-dependent manner with a threshold dose ranging from 0.5 to $1 \mathrm{ng}$ through intracerebroventricular (i.c.v.) injection (Figure 3), corresponding to the physiological range observed in the brain of normal newts (Matsunaga et al., 2004). Therefore, $7 \alpha$-hydroxypregnenolone may act as a novel neuronal modulator to stimulate locomotor activity of male newts, and the increase in locomotor activity of male newts that occurs during the spring breeding period may be ascribed to an increase in the production of $7 \alpha$-hydroxypregnenolone.

Because the male quail displays a robust locomotor activity rhythm when held under typical light/dark lighting schemes (Wilson, 1972; Wada, 1979; see Diurnal Changes in 7 $\alpha$-Hydroxypregnenolone Synthesis and Locomotor Activity and their Regulatory Mechanisms for further discussion), this bird has also served as an appropriate animal model to investigate the biological action of $7 \alpha-$ and $7 \beta$-hydroxypregnenolone. Both neurosteroids were therefore administered i.c.v. to male quail during night, when activity is low, to examine whether they affect locomotor activity (Tsutsui et al., 2008; see Diurnal Changes in $7 \alpha$-Hydroxypregnenolone Synthesis and Locomotor Activity and their Regulatory Mechanisms for further discussion). A stimulatory dose-dependent effect of $7 \alpha$-hydroxypregnenolone was observed with effective doses ranging between 10 and $100 \mathrm{ng}$ (Tsutsui et al., 2008). In contrast, even at the highest dose tested (100 ng), $7 \beta$-hydroxypregnenolone did not

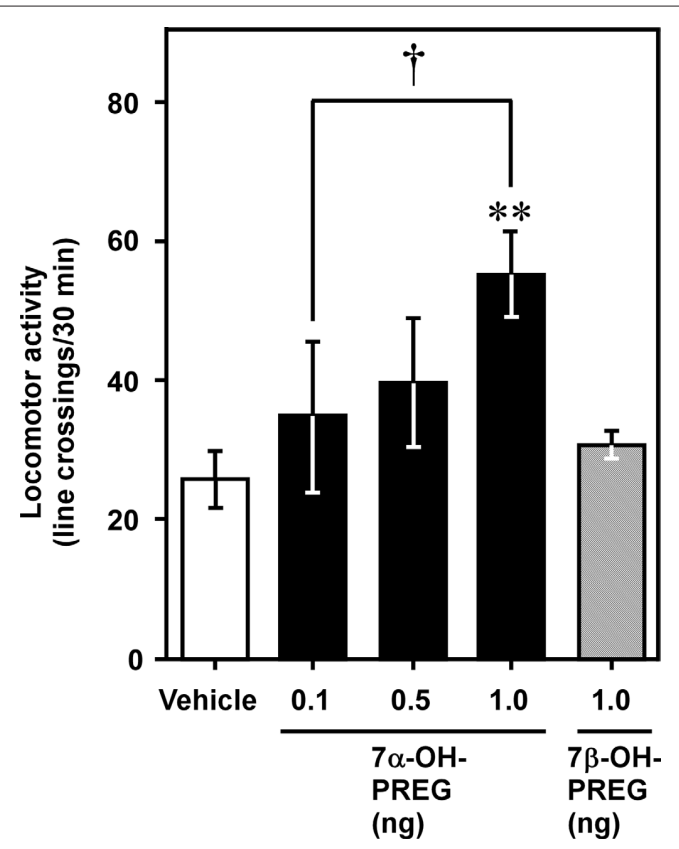

FIGURE 3 | Effect of 7 $\alpha$-hydroxypregnenolone on locomotor activity of male newt. Male newts in the non-breeding period received an i.c.v. injection of vehicle ( $n=7), 7 \alpha$-hydroxypregnenolone ( $7 \alpha-\mathrm{OH}$ PREG; 0.1 and $0.5 \mathrm{ng}$ : $n=6 ; 1 \mathrm{ng}: n=7$ ), or 7 $\beta$-hydroxypregnenolone (7$\beta-O H$ PREG; $1 \mathrm{ng}: n=6$ ). Each column and vertical line represents the mean \pm SEM total number of crossings. ${ }^{* *} p<0.01$ vs. vehicle, ${ }^{\dagger} p<0.05$ vs. 0.1 ng of $7 \alpha-$ hydroxypregnenolone injection by one-way ANOVA, followed by Duncan's multiple range test. Adapted from Matsunaga et al. (2004). 
influence locomotor activity (Tsutsui et al., 2008). It thus appears that $7 \alpha$-hydroxypregnenolone, but not $7 \beta$-hydroxypregnenolone, acts as a neuronal modulator to stimulate locomotor activity in male quail.

\section{MODE OF ACTION OF 7 $\alpha$-HYDROXYPREGNENOLONE ON LOCOMOTOR ACTIVITY}

To investigate the mode of action of $7 \alpha$-hydroxypregnenolone on locomotion, the concentrations of several monoamines (norepinephrine, epinephrine, dopamine, and 5-hydroxytryptamine) were measured by HPLC-electrochemical detection (ECD) 5 min after an i.c.v. injection of $7 \alpha$-hydroxypregnenolone to non-breeding male newts (Matsunaga et al., 2004). $7 \alpha$-Hydroxypregnenolone significantly increased the concentration of dopamine in the male newt brain, particularly in the rostral brain region including the striatum, which is known to be involved in the regulation of locomotor behavior (Matsunaga et al., 2004). In contrast, there were no significant differences in the concentrations of other monoamines, i.e., norepinephrine, epinephrine, and 5-hydroxytryptamine (Matsunaga et al., 2004). In vitro experiments further revealed that $7 \alpha$-hydroxypregnenolone treatment results in a concentration-dependent increase in the release of dopamine from cultured male newt brain tissue after a 10-min incubation (Matsunaga et al., 2004). The threshold concentration ranged between $10^{-8}$ and $10^{-7} \mathrm{M}$ (Matsunaga et al., 2004). The effect of $7 \alpha$-hydroxypregnenolone on locomotion was abolished by administration of haloperidol or sulpiride, two dopamine $\mathrm{D}_{2}$ receptor antagonists (Matsunaga et al., 2004). In contrast, the dopamine $\mathrm{D}_{1}$ receptor antagonist $\mathrm{SCH} 23390$ did not block the effect of $7 \alpha$-hydroxypregnenolone (Matsunaga et al., 2004). These results indicate that the stimulatory effect of $7 \alpha$-hydroxypregnenolone on locomotor activity is mediated through dopamine $\mathrm{D}_{2}$ receptors. To recapitulate, $7 \alpha$-hydroxypregnenolone synthesized actively in the diencephalon and rhombencephalon, by acting on dopaminergic neurons localized in the posterior tuberal (PT) nucleus and ventral tegmental area (VTA), may induce dopamine release from their terminals in the rostral brain region, notably in the striatum and nucleus accumbens (NA), and consequently increase locomotor activity of newts (Figure 4; Matsunaga et al., 2004).

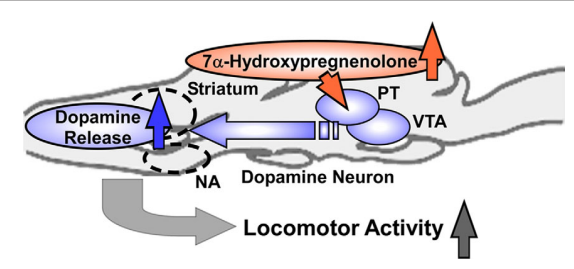

FIGURE 4 | Schematic model depicting the possible action of $7 \alpha$-hydroxypregnenolone on the regulation of locomotor activity in male newt. $7 \alpha$-Hydroxypregnenolone synthesized actively in the diencephalon and rhombencephalon, by acting on dopaminergic neurons localized in the posterior tuberal (PT) nucleus and ventral tegmental area (VTA), may induce dopamine release from their terminals in rostral brain regions, notably in the striatum and nucleus accumbens (NA), and consequently increase locomotor activity of male newt. See the text for details.
To identify the cells producing $7 \alpha$-hydroxypregnenolone in the quail brain, we have investigated the expression of $\mathrm{P} 40_{7 \alpha}$ by in situ hybridization. In the male diencephalon, the expression of $\mathrm{P} 40_{7 \alpha}$ mRNA was localized in the nucleus preopticus medialis (POM), the nucleus paraventricularis magnocellularis (PVN), the nucleus ventromedialis hypothalami (VMN), the nucleus dorsolateralis anterior thalami (DLA), and the nucleus lateralis anterior thalami (LA; Tsutsui et al., 2008). In quail as in newt (Matsunaga et al., 2004), $7 \alpha$-hydroxypregnenolone increased the concentration of dopamine in the telencephalic region that encompasses the striatum (Sanberg, 1983; Sharp et al., 1987; Bardo et al., 1990). In birds, dopaminergic neurons that are located in the mesencephalic region, including the ventral tegmental area (VTA) and the substantia nigra $(\mathrm{SN})$, project to the telencephalon notably the striatum (Mezey and Csillag, 2002; Hara et al., 2007). Interestingly, in birds as in mammals, the telencephalic region is enriched with dopamine $\mathrm{D}_{1}$ and $\mathrm{D}_{2}$ receptors (Ball et al., 1995; Levens et al., 2000). Thus, the stimulatory effect of $7 \alpha$-hydroxypregnenolone on locomotor activity in male quail may be mediated by the dopaminergic system as previously shown in male newt. In sum, $7 \alpha$-hydroxypregnenolone synthesized actively in the diencephalon, by acting on dopamine neurons localized in the VTA and SN, may induce dopamine release from their termini in the striatum, and consequently increase locomotor activity in male quail.

The fact that $7 \alpha$-hydroxypregnenolone acutely increases locomotor activity in newt and quail suggests that the neurosteroid may act through a non-genomic rather than a genomic mechanism. In rat, the progesterone metabolite $3 \alpha, 5 \alpha$-THP (allopregnanolone) exerts its effects on locomotion (Wieland et al., 1995) and dopamine release (Bullock et al., 1997; Rougé-Pont et al., 2002) via a nongenomic pathway. Allopregnanolone may act through modulation of $\mathrm{GABA}_{\mathrm{A}}$ receptors, since allopregnanolone is a potent allosteric modulator of $\mathrm{GABA}_{\mathrm{A}}$ receptors (Paul and Purdy, 1992; Lambert et al., 1995) and dopaminergic neurons are regulated by GABAergic transmission (Laviolette and van der Kooy, 2001). Whether the acute actions of $7 \alpha$-hydroxypregnenolone on dopamine release and locomotor activity in newt and quail are mediated through $\mathrm{GABA}_{\mathrm{A}}$ receptors remain to be determined.

\section{SEX DIFFERENCES IN 7 $\alpha$-HYDROXYPREGNENOLONE SYNTHESIS AND LOCOMOTOR ACTIVITY}

In birds (Tsutsui et al., 2008) as in other vertebrates (Tsutsui, 1931; Iwata et al., 2000), the locomotor activity of males is known to be higher than that of females (Figure 5A). In quail, the production and concentration of $7 \alpha$-hydroxypregnenolone in the male diencephalon were much higher than in female (Figures 5B,C; Tsutsui et al., 2008). Such a sexual dimorphism only occurs in the diencephalon (Tsutsui et al., 2008). There are similar sex differences in 3 $\beta$-HSD and P450arom in the avian brain (Schlinger and Callard, 1987; Soma et al., 2004; Tam and Schlinger, 2007). In view of the sex difference in $7 \alpha$-hydroxypregnenolone biosynthesis and concentration in the quail diencephalon (Figures 5B,C; Tsutsui et al., 2008), it seemed possible that this neurosteroid actively plays a role in the control of locomotor activity only in males. (Tsutsui et al., 2008) In support of this notion, administration of the $\mathrm{P} 450$ inhibitor ketoconazole in male quail decreased locomotor activity (Tsutsui et al., 2008). Unlike 


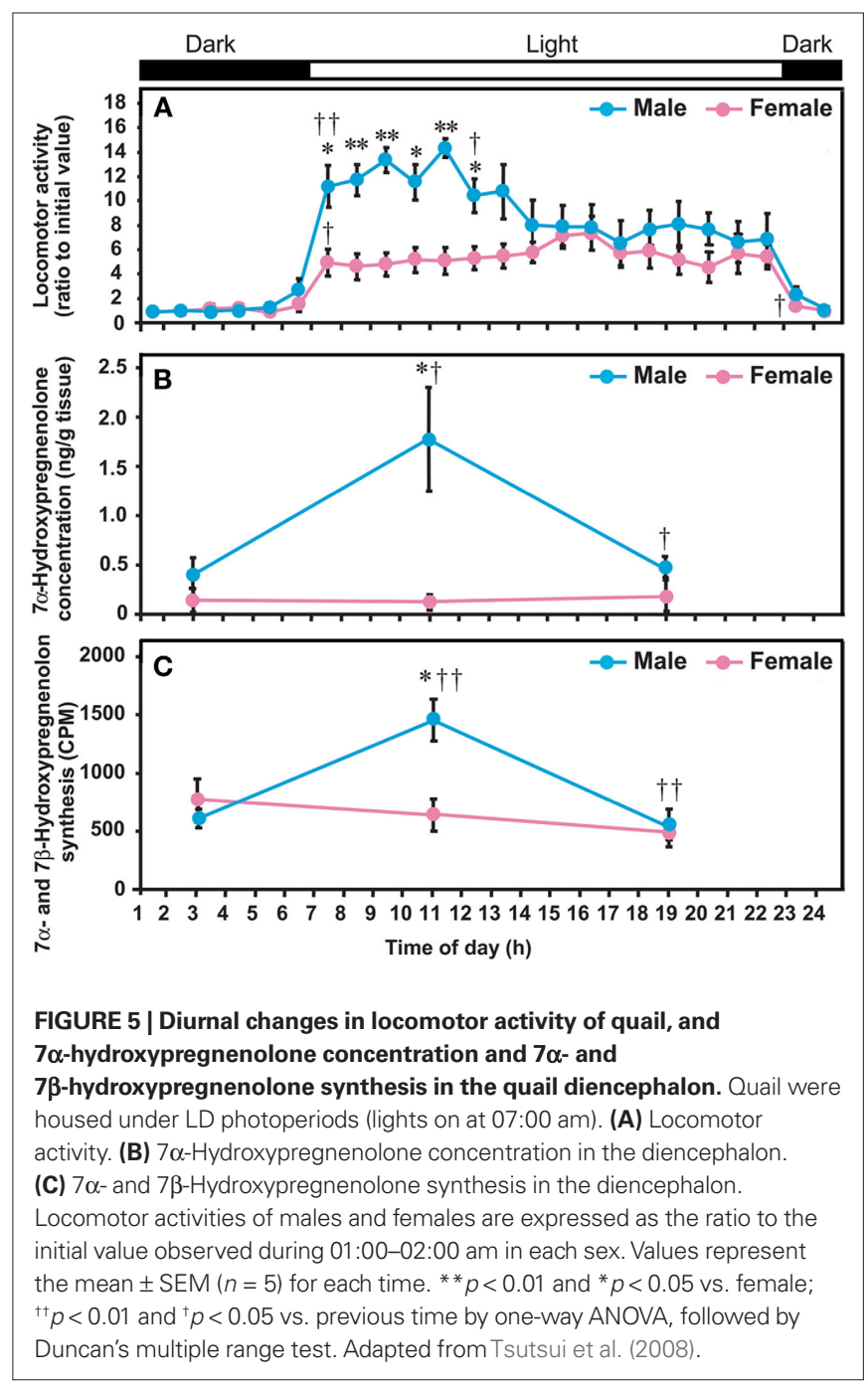

males, $7 \alpha$-hydroxypregnenolone administration did not increase locomotor activity in females (Tsutsui et al., 2008). This observation suggests that the receptor for $7 \alpha$-hydroxypregnenolone is not present or is otherwise inactive in the female. In addition, the rate of $7 \alpha$-hydroxypregnenolone biosynthesis and the tissue concentration of $7 \alpha$-hydroxypregnenolone were significantly lower in the female quail diencephalon than in male (Figures 5B,C; Tsutsui et al., 2008). These data suggest that $7 \alpha$-hydroxypregnenolone may not affect locomotor activity in the female.

In newt, the biosynthesis and concentration of $7 \alpha$-hydroxypregnenolone in the male brain were also higher than in the female (Figures 7A,B; Matsunaga et al., 2004; Haraguchi et al., 2010). It is well known that sexually mature male newts in the breeding period move around much more than the females, searching sexually mature female partners or courting females prior to sperm transfer (Tsutsui, 1931; Iwata et al., 2000). It is therefore possible that, in newt as in quail, $7 \alpha$-hydroxypregnenolone may specifically affect the activity of the male brain. Taken together, these observations suggest that $7 \alpha$-hydroxypregnenolone may play a crucial role in the control of sex-dependent locomotor activity in vertebrates.

\section{DIURNAL AND SEASONAL CHANGES IN \\ $7 \alpha$-HYDROXYPREGNENOLONE SYNTHESIS AND LOCOMOTOR ACTIVITY AND THEIR REGULATORY MECHANISMS DIURNAL CHANGES IN $7 \alpha$-HYDROXYPREGNENOLONE SYNTHESIS AND LOCOMOTOR ACTIVITY AND THEIR REGULATORY MECHANISMS}

To further investigate the functional significance of $7 \alpha$-hydroxypregnenolone in the regulation of locomotor activity, the correlation between locomotor activity and the concentrations of diencephalic $7 \alpha$-hydroxypregnenolone was studied in male quail exposed to daily photoperiods of $16 / 8 \mathrm{~h} \mathrm{light/dark} \mathrm{(LD;} \mathrm{lights} \mathrm{on} \mathrm{at}$ 07:00 am, off at 11:00 pm). Locomotor activity of males was much higher than that of females from the time of lights on until noon, but thereafter decreased to female levels (Figure 5A; Tsutsui et al., 2008). In males, these changes in locomotor activity were correlated with concentrations of diencephalic $7 \alpha$-hydroxypregnenolone, the maximum value occurring at 11:00 am when locomotor activity was high (Figures 5A,B; Tsutsui et al., 2008). The functional significance of this correlation is supported by the observation that administration of ketoconazole, an inhibitor of P450s, inhibits locomotor activity at 11:00 am (Tsutsui et al., 2008). Thus, the increase in diencephalic $7 \alpha$-hydroxypregnenolone may be responsible, at least in part, for the higher locomotor activity in males. As mentioned in Section "Sex Differences in $7 \alpha$-Hydroxypregnenolone Synthesis and Locomotor Activity," the low level of $7 \alpha$-hydroxypregnenolone biosynthesis and concentration in the female diencephalon suggests that this neurosteroid may not play a role in female locomotor activity (Figures 5A-C).

Further studies were undertaken to elucidate the mechanism regulating diurnal changes in $7 \alpha$-hydroxypregnenolone biosynthesis and $7 \alpha$-hydroxypregnenolone-dependent locomotor activity. Melatonin is known to be also involved in the regulation of locomotor activity in birds (Binkley et al., 1971; John et al., 1978; Cassone and Menaker, 1984; Chabot and Menaker, 1992; Hau and Gwinner, 1994; Warren and Cassone, 1995; Murakami et al., 2001), which suggested that melatonin may regulate diencephalic $7 \alpha$-hydroxypregnenolone biosynthesis, and thereby influence locomotor activity. To test this hypothesis, experiments involving melatonin manipulation were performed in male quail. Combination of pinealectomy $(\mathrm{Px})$ and orbital enucleation (Ex) increased after 1 week the production and concentration of $7 \alpha$-hydroxypregnenolone (Figures $6 \mathrm{~A}, \mathrm{~B}$ ) and the expression of $\mathrm{P} 40_{7 \alpha}$ in the quail diencephalon (Figure 6C). Conversely, melatonin administration to Px/Ex quail decreased the production and concentration of $7 \alpha$-hydroxypregnenolone and the expression of $\mathrm{P} 40_{7 \alpha}$ in the diencephalon (Figures $6 \mathrm{~A}-\mathrm{C}$; Tsutsui et al., 2008). Further, the inhibitory effect of melatonin on $7 \alpha$-hydroxypregnenolone synthesis was abolished by luzindole, a melatonin receptor antagonist (Tsutsui et al., 2008). These data indicate that melatonin acts to reduce $\mathrm{P} 450_{7 \alpha}$ expression through melatonin receptor-mediated mechanisms. Melatonin derived from the pineal gland and eyes therefore may act as an inhibitory factor of $7 \alpha$-hydroxypregnenolone biosynthesis in the quail. This notion is supported by earlier studies indicating that melatonin treatment decreases locomotor activity in quail (Murakami et al., 2001; Nakahara et al., 2003) and other birds (Murakami et al., 2001). To the best of our knowledge, this is the first observation showing that melatonin regulates neurosteroid biosynthesis in the brain of vertebrates (for a review, see Tsutsui et al., 2009b). 

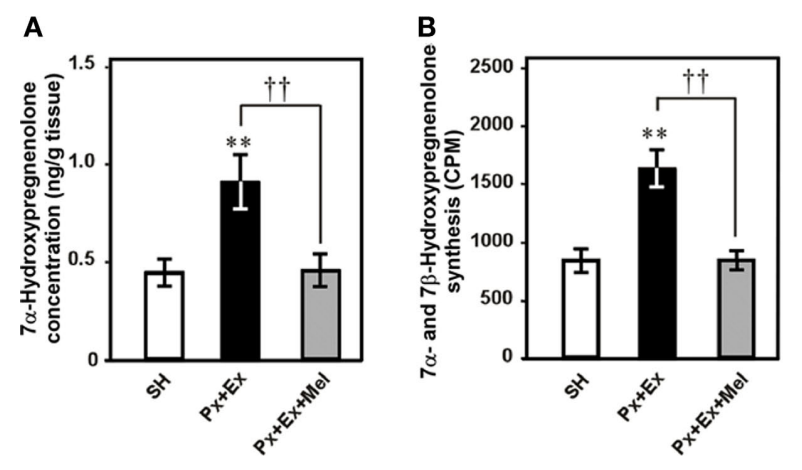

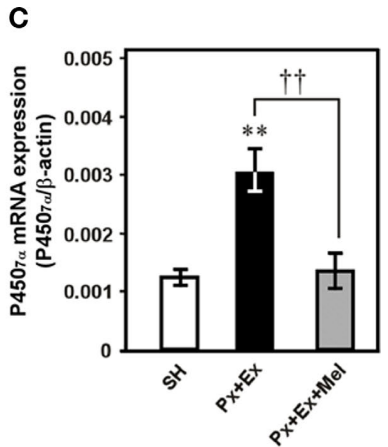

FIGURE 6 | Effects of pinealectomy combined with orbital enucleation $(P x+E x)$ and melatonin administration to $P x+E x$ quail $(P x+E x+$ Mel) on $7 \alpha$-hydroxypregnenolone concentration, $7 \alpha$ - and $7 \beta$-hydroxypregnenolone synthesis, and $\mathrm{P450}_{7 \alpha} \mathrm{mRNA}$ expression in the diencephalon of male quail. (A) $7 \alpha$-Hydroxypregnenolone concentration in the diencephalon. (B) $7 \alpha$ - and
$7 \beta$-Hydroxypregnenolone synthesis in the diencephalon. (C) P450 ${ }_{7 \alpha} \mathrm{mRNA}$ expression in the diencephalon. Each column and vertical line represents the mean $\pm \operatorname{SEM}(n=5) .{ }^{* *} p<0.01$ vs. sham-operation $(\mathrm{SH}) ;{ }^{+\dagger} p<0.01 \mathrm{Px}+$ Ex vs. Px + Ex + Mel by one-way ANOVA, followed by Duncan's multiple range test. Adapted from Tsutsui et al. (2008).
In quail, as in all vertebrates, the nocturnal secretion of melatonin is night-length dependent (Cockrem and Follett, 1985), and the onset of melatonin secretion occurs soon after the onset of darkness (Kumar and Follett, 1993). Therefore, the increase in $7 \alpha$-hydroxypregnenolone biosynthesis in the brain of male quail during the light period is likely to be a result of the decrease in endogenous melatonin secretion. Since $7 \alpha$-hydroxypregnenolone stimulates locomotor activity, it is proposed that, in male quail, this neurosteroid plays a crucial role in diurnal changes in locomotor activity through the action of melatonin.

In birds and vertebrates in general, locomotor activity undergoes a circadian rhythm (Saper et al., 2005) controlled by diurnal rhythm of melatonin secretion (Binkley et al., 1971; John et al., 1978; Cassone and Menaker, 1984; Chabot and Menaker, 1992; Hau and Gwinner, 1994; Warren and Cassone, 1995). However, the molecular mechanisms underlying this neurohormonal regulation of behavior are poorly understood. The discovery of the role of $7 \alpha$-hydroxypregnenolone in mediating the action of melatonin on diurnal locomotor rhythmicity is an important step in understanding these mechanisms (Tsutsui et al., 2008). A similar mechanism may underlie the regulation of diurnal locomotor rhythms in other vertebrates (for reviews, see Tsutsui et al., 2009a,b, 2010), since $7 \alpha$-hydroxypregnenolone is also present in the brains of newts (Matsunaga et al., 2004) and mammals (Akwa et al., 1992; Doostzadeh and Morfin, 1997; Weill-Engerer et al., 2003; Yau et al., 2003).

\section{SEASONAL CHANGES IN 7 $\alpha$-HYDROXYPREGNENOLONE SYNTHESIS AND LOCOMOTOR ACTIVITY AND THEIR REGULATORY MECHANISMS}

Tounderstand the functional significance of $7 \alpha$-hydroxypregnenolone, seasonal changes in $7 \alpha$-hydroxypregnenolone biosynthesis and concentration in the brain were also demonstrated in the newt $C$. pyrrhogaster, a seasonally breeding wild animal (Matsunaga et al., 2004; Haraguchi et al., 2010). Seasonally breeding wild animals are suitable models to investigate such changes in neurosteroid production. Both the biosynthesis and concentration of $7 \alpha$-hydroxypregnenolone in the male brain markedly changed during the annual breeding cycle and were maximum in the spring breeding period (Figures 7A,B; Matsunaga et al., 2004; Haraguchi et al., 2009, 2010). Similar seasonal changes in the expression of newt $\mathrm{P} 40_{7 \alpha}$, that catalyzes the formation of $7 \alpha$-hydroxypregnenolone, occurred in the male brain (Figure 7C; Haraguchi et al., 2010). As mentioned in Section "Sex Differences in $7 \alpha$-Hydroxypregnenolone Synthesis and Locomotor Activity," it has been previously reported that sexually mature male newts in the spring breeding period move around much more than females (Tsutsui, 1931; Iwata et al., 2000). These findings suggest that the increase in locomotor activity of male newts in the spring breeding period can be accounted for an increase in $7 \alpha$-hydroxypregnenolone biosynthesis in the brain. In contrast to males, $7 \alpha$-hydroxypregnenolone levels in the brain of females did not vary significantly and are constantly low (Figures 7A-C; Haraguchi et al., 2010). Accordingly, the lower locomotor activity in females could be ascribed to a lower level of $7 \alpha$-hydroxypregnenolone in their brain.

We have examined the mechanism that regulates seasonal changes in $7 \alpha$-hydroxypregnenolone biosynthesis in the male brain. In the newt, prolactin (PRL) induces development of sex characters (Dent, 1975); migration to water, in which sperm transfer and oviposition take place (Chadwick, 1941); development of the abdominal gland of the cloaca (Kikuyama et al., 1975), which secretes female-attracting pheromones (Kikuyama et al., 1995); enlargement of Mauthner neurons, which facilitate the rapid tail-vibration performed by male newts during courtship (Matsumoto et al., 1995); and expression of courtship behavior (Toyoda et al., 1993). Plasma PRL levels in the newt are elevated during the breeding period (Matsuda et al., 1990; Mosconi et al., 1994) and it has been shown that PRL acts directly on the brain to regulate courtship behavior in the male newt (Toyoda et al., 2005). Based on these observations, we hypothesized that PRL may act on the brain to increase $7 \alpha$-hydroxypregnenolone biosynthesis, thus enhancing locomotor activity of male newts during the breeding period. A recent study has provided evidence that PRL is an important regulator of $7 \alpha$-hydroxypregnenolone production (Haraguchi et al., 2010). Hypophysectomy (Hypox) decreased after 2 weeks $7 \alpha$-hydroxypregnenolone biosynthesis and concentration in the brain of sexually mature males (Figure 8), suggesting that some pituitary hormone(s) may be involved in the regulation of $7 \alpha$-hydroxypregnenolone biosynthesis in the 


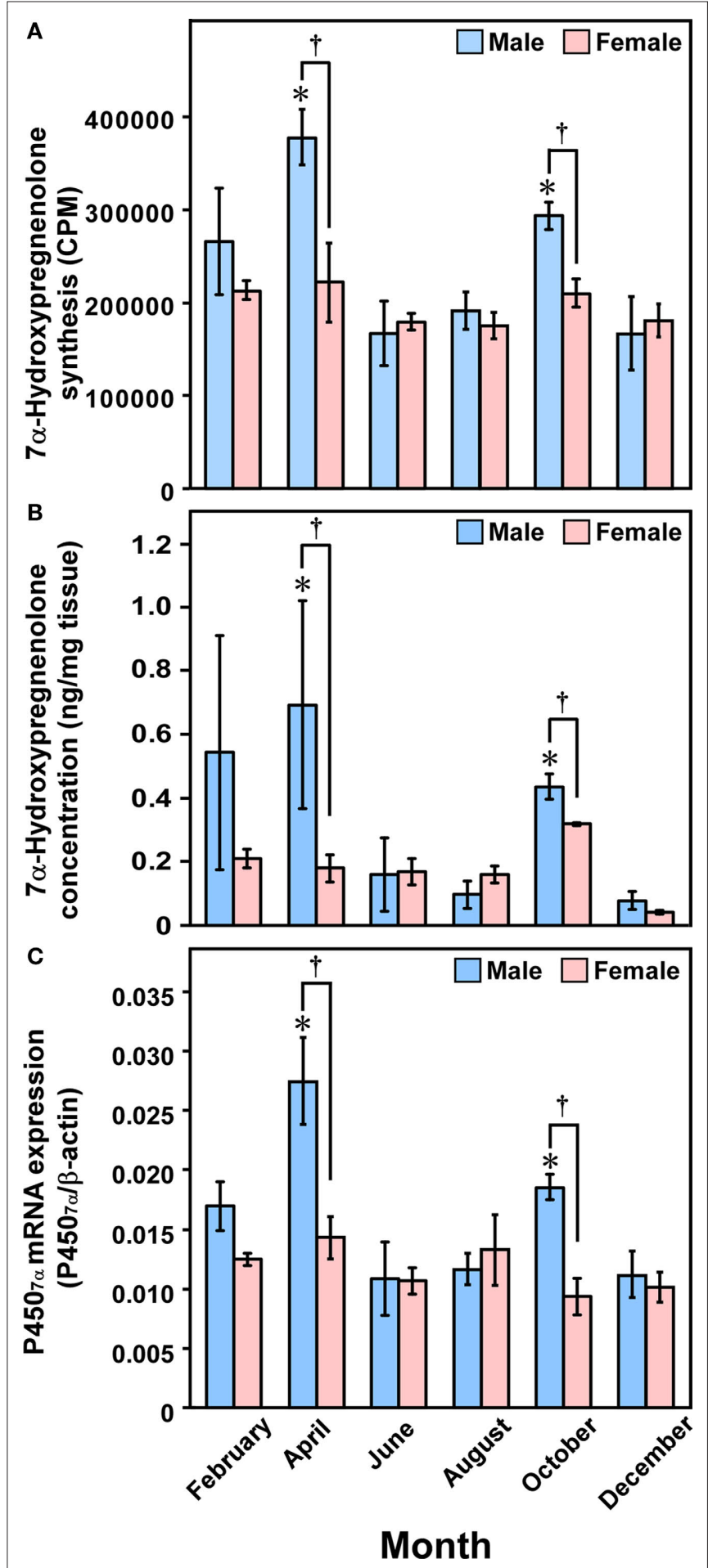

FIGURE 7 | Seasonal changes in $7 \alpha$-hydroxypregnenolone synthesis and concentration, and $\mathrm{P450}_{7 \alpha}$ mRNA expression in the newt brain.

(A) Seasonal changes in $7 \alpha$-hydroxypregnenolone synthesis in the brain.

(B) Seasonal changes in 7 $\alpha$-hydroxypregnenolone concentration in the brain. (C) Seasonal changes in $\mathrm{P}_{450}$ mRNA expression in the brain. Each column and vertical line represents the mean $\pm \operatorname{SEM}(n=6) .{ }^{*} p<0.05$ vs. December; ${ }^{\dagger} p<0.05$ male vs. female by two-way ANOVA, followed by Tukey-Kramer test. Adapted from Haraguchi et al. (2010). brain (Haraguchi et al., 2010). Administration of PRL but not gonadotropins (GTHs) to Hypox male newts caused a dosedependent increase in $7 \alpha$-hydroxypregnenolone biosynthesis (Figures 8A,B) and concentration in the brain (Haraguchi et al., 2010). Reciprocally, administration of anti-newt PRL serum dose-dependently decreased $7 \alpha$-hydroxypregnenolone biosynthesis (Haraguchi et al., 2010). Accordingly, PRL secreted by the adenohypophysis can be regarded as a major factor regulating $7 \alpha$-hydroxypregnenolone biosynthesis. This is a previously undescribed role of the adenohypophyseal hormone in the regulation of neurosteroidogenesis in the brain in any vertebrate. Further studies are needed to clarify whether a similar hormonal mechanism regulating $7 \alpha$-hydroxypregnenolone biosynthesis occurs in other vertebrates.

In contrast to male newts, no seasonal changes in $7 \alpha$-hydroxypregnenolone biosynthesis and concentration, and $\mathrm{P}_{450}$ mRNA expression were observed in female newts (Figure 7; Haraguchi et al., 2010). Interestingly, plasma PRL levels in the male newt $C$. pyrrhogaster exhibit marked seasonal changes during the annual breeding cycle and are maximum in the spring breeding period. In contrast, plasma PRL levels in females are constantly low (Matsuda et al., 1990). Such a sex difference in the seasonal changes in plasma PRL levels may account for the absence of seasonal changes in $7 \alpha$-hydroxypregnenolone biosynthesis and concentration, and $\mathrm{P} 450_{7 \alpha}$ mRNA expression in the female brain.

To understand the mode of action of PRL in the regulation of $7 \alpha$-hydroxypregnenolone biosynthesis, we have determined the site of expression of $\mathrm{P} 40_{7 \alpha}$ and looked for colocalization of $\mathrm{P} 450_{7 \alpha}$ mRNA and PRL receptor (PRLR) in sexually mature male newts. $\mathrm{P}_{45} 0_{7 \alpha}$ mRNA-positive cells were localized mainly in the anterior preoptic area (POA), magnocellular preoptic nucleus $(\mathrm{Mg})$, and tegmental area (TA) in the brain (Haraguchi et al., 2010). However, PRLR-like immunoreactivity was found only in the $\mathrm{Mg}$ (Haraguchi et al., 2010). Thus, the major, but perhaps not exclusive, targets of PRL action to increase $7 \alpha$-hydroxypregnenolone biosynthesis are the $\mathrm{P}_{450_{7 \alpha}}$-positive cells in the $\mathrm{Mg}$ (Figure 9). The $\mathrm{Mg}$ is sexually dimorphic both in term of response to pheromones and neuroanatomical aspect (Govek and Swann, 2007). In particular, the Mg possesses more neurons in the male than in the female (Govek et al., 2003). Electrolytic lesions that include the Mg immediately and permanently eliminate male copulatory behavior in the hamster (Powers et al., 1987). In newt (Giorgio et al., 1982; Toyoda et al., 1993), the involvement of PRL in eliciting courtship behavior of males has been reported. Accordingly, it is possible that PRL may also induce the expression of courtship behavior by increasing $7 \alpha$-hydroxypregnenolone synthesis in the $\mathrm{Mg}$ of sexually mature male newts. In addition, it has been reported that PRL acts on the $\mathrm{Mg}$ to cause the release of arginine vasotocin (AVT; Hasunuma et al., 2007; Kikuyama et al., 2009). AVT is known to be an important factor for the expression of courtship behavior (Toyoda et al., 2003). Therefore, it is possible that PRL-induced courtship behavior in male newt is mediated by AVT release, which may act to stimulate biosynthesis of $7 \alpha$-hydroxypregnenolone.

On the other hand, it is known that, in mammals, PRL is synthesized in not only the adenohypophysis but also a subset of hypothalamic neurons projecting throughout the brain 


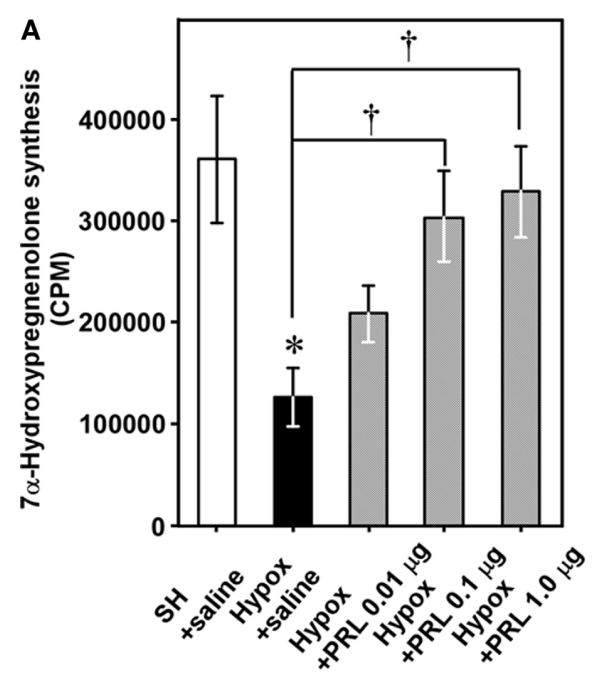

FIGURE 8 | Effects of hypophysectomy (Hypox) and administration of PRL or GTH on $7 \alpha$-hydroxypregnenolone synthesis and concentration in the brain of breeding male newts. (A) Effects of Hypox and i.c.v. injection of various doses of PRL on $7 \alpha$-hydroxypregnenolone synthesis. (B) Effects of Hypox and

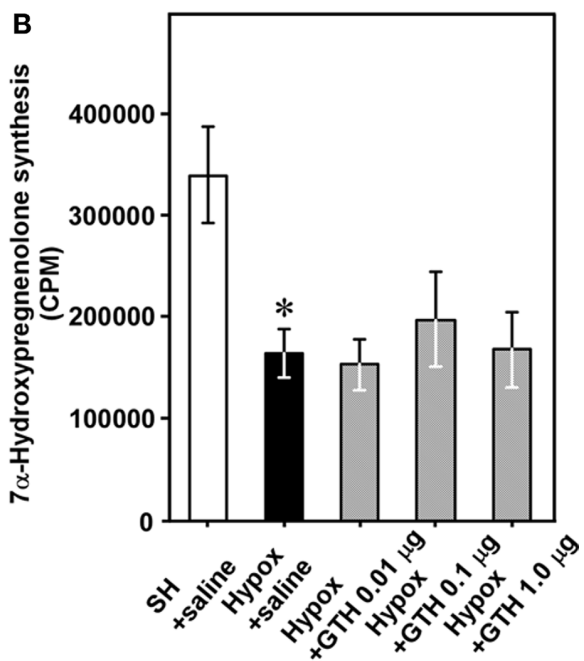

i.c.v. injection of various doses of GTH on $7 \alpha$-hydroxypregnenolone synthesis. Each column and vertical line represents the mean \pm SEM $(n=6) .{ }^{*} p<0.05$ vs. sham-operation (SH) plus saline; ${ }^{\dagger} p<0.05$ vs. Hypox plus saline by one-way ANOVA, followed by Tukey-Kramer test. Adapted from Haraguchi et al. (2010).

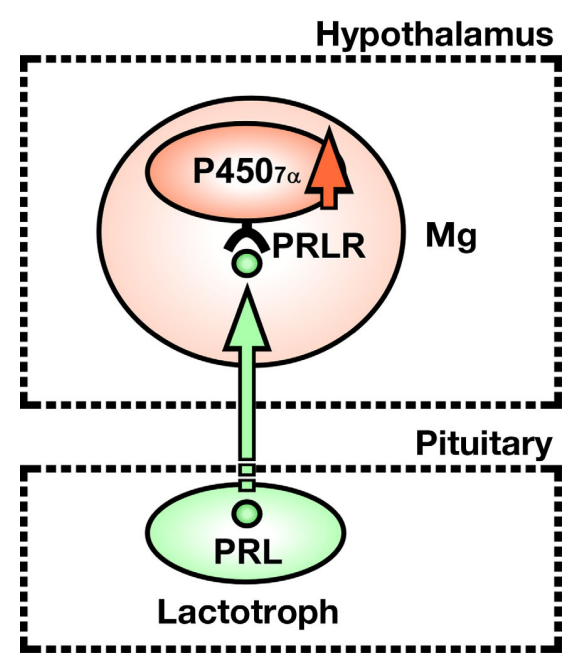

FIGURE 9 | Schematic model depicting the possible action of PRL on the expression of $\mathrm{P450}_{7 \alpha}$ in the magnocellular preoptic nucleus $(\mathrm{Mg})$ of male newt. PRL synthesized in the adenohypophysis, by acting on $\mathrm{Mg}$ neurons in the hypothalamus, may induce the expression of $\mathrm{P} 450_{7 \alpha} . P 450_{7 \alpha}$ and $\mathrm{PRL}$ receptor (PRLR) are colocalized in Mg neurons. Thus, the major, but perhaps not exclusive, targets of PRL action to increase $7 \alpha$-hydroxypregnenolone biosynthesis are $\mathrm{Mg}$ neurons expressing $\mathrm{P}^{450} 0_{7 \alpha}$. See the text for details.

(Fuxe et al., 1977; De Vito, 1988; Emanuele et al., 1992). In preliminary experiments, we performed RT-PCR using newt brain total RNA with newt PRL cDNA-specific primers and detected specific amplification (unpublished data). In contrast, by an immunohistochemical method using anti-newt PRL antiserum, we could not detect PRL immunoreactivity in the newt brain. These results suggest that PRL is expressed in the newt brain but the expression level might be very low. Thus, the localization and function of newt brain PRL are still unclear. It is considered that adenohypophysis PRL is more important than brain PRL in the expressions of locomotor activity and courtship behavior, inasmuch as an increase in plasma PRL levels in breeding male newts (Matsuda et al., 1990; Mosconi et al., 1994) and the suppression of courtship behavior in Hypox male newts (Toyoda et al., 1993) have also been reported. In the choroid plexus of newt, dense PRLR immunoreactivity and PRLR mRNA signals were observed the epithelial cells (Hasunuma et al., 2005). In mammals, choroid plexus PRLR has been proposed to be involved in the transport of PRL from blood into the cerebrospinal fluid (Walsh et al., 1987). Thus, PRL transported from the blood into the cerebrospinal fluid via the choroid plexus receptor is considered to play an important role in the expression of courtship behavior, although a possible contribution of PRL transported to the brain through retrograde blood flow by the portal system as reported in mammals (Oliver et al., 1977; Porter et al., 1978) cannot be excluded.

\section{CONCLUSION}

The brain of vertebrates possesses several kinds of steroidogenic enzymes and produces a variety of neurosteroids. However, the biosynthetic pathway of neurosteroids in the brain was not completely elucidated. A newly discovered amphibian and avian neurosteroid, $7 \alpha$-hydroxypregnenolone, acts as an important factor stimulating locomotor activity. The stimulatory action of $7 \alpha$-hydroxypregnenolone is mediated by the dopaminergic system. $7 \alpha$-Hydroxypregnenolone apparently functions in male but not in female. Melatonin acts on the neurons expressing $\mathrm{P}_{450}$ to regulate $7 \alpha$-hydroxypregnenolone biosynthesis, thus inducing diurnal locomotor changes in males. PRL, an adenohypophyseal hormone, also acts on the neurons expressing $\mathrm{P} 450_{7 \alpha}$ to regulate $7 \alpha$-hydroxypregnenolone biosynthesis, thus inducing seasonal 
locomotor changes in males. These recent findings indicate that $7 \alpha$-hydroxypregnenolone-producing neurons may play a pivotal role in the integration of circadian and seasonal information that affects locomotor activity in amphibians and birds.

\section{REFERENCES}

Akwa, Y., Morfin, R. F., Robel, P., and Baulieu, E.-E. (1992). Neurosteroid metabolism: $7 \alpha$-hydroxylation of dehydroepiandrosterone and pregnenolone by rat brain microsomes. Biochem. J. 288, 959-964.

Akwa, Y., Sananés, N., Gouézou, M., Robel, P., Baulieu, E.-E., and Le Goascogne, C. (1993). Astrocytes and neurosteroids: metabolism of pregnenolone and dehydroepiandrosterone. Regulation by cell density. J. Cell Biol. 121, 135-143.

Ball, G. F., Casto, J. M., and Balthazart, J. (1995). Autoradiographic localization of D1-like dopamine receptors in the forebrain of male and female Japanese quail and their relationship with immunoreactive tyrosine hydroxylase. J. Chem. Neuroanat. 9, 121-133.

Balthazart, J., Foidart, A., and Harada, N. (1990a). Immunocytochemical localization of aromatase in the brain. Brain Res. 514, 327-333.

Balthazart, J., Foidart, A., Surlemont, C., Vockel, A., and Harada, N. (1990b). Distribution of aromatase in the brain of the Japanese quail, ring dove, and zebra finch: an immunocytochemical study. J. Comp. Neurol. 301, 276-288.

Balthazart, J., Foidart, A., Surlemont, C., and Harada, N. (1991). Neuroanatomical specificity in the colocalization of aromatase and estrogen receptors. J. Neurobiol. 22, 143-157.

Bardo, M. T., Bowling, S. L., and Pierce, R. C. (1990). Changes in locomotion and dopamine neurotransmission following amphetamine, haloperidol, and exposure to novel environmental stimuli. Psychopharmacology 101, 338-343.

Baulieu, E.-E. (1991). Neurosteroids: a new function in the brain. Biol. Cell 71, 3-10.

Baulieu, E.-E. (1997). Neurosteroids: of the nervous system, by the nervous system, for the nervous system. Recent Prog. Horm. Res. 52, 1-32.

Baulieu, E.-E., and Robel, P. (1990). Neurosteroids: a new brain function? J. Steroid Biochem. Mol. Biol. 37, 395-403.

Beaujean, D., Mensah-Nyagan, A. G., Do-Rego, J. L., Luu-The, V., Pelletier, G., and Vaudry, H. (1999). Immunocytochemical localization and biological activity of hydroxysteroid sulfotransferase in the frog brain. J. Neurochem. 72, 848-857.
Binkley, S., Kluth, E., and Menaker, M. (1971). Pineal function in sparrows: circadian rhythms and body temperature. Science 174, 311-314.

Bruzzone, F., Do-Rego, J. L., Luu-The, V., Pelletier, G., Vallarino, M., and Vaudry, H. (2010). Immunohistochemical localization and biological activity of $3 \beta$-hydroxysteroid dehydrogenase and $5 \beta$-reductase in the brain of the frog, Rana esculenta, during development. J. Chem. Neuroanat. 39, 35-50.

Bullock, A. E., Clark, A. L., Grady, S. R., Robinson, S. F., Slobe, B. S., Marks, M. J., and Collins, A. C. (1997). Neurosteroids modulate nicotinic receptor function in mouse striatal and thalamic synaptosomes. J. Neurochem. 68, 2412-2423.

Cassone, V. M., and Menaker, M. (1984). Is the avian circadian system a neuroendocrine loop? J. Exp. Zool. 232, 539-549.

Chabot, C. C., and Menaker, M. (1992). Circadian feeding and locomotor rhythms in pigeons and house sparrows. J. Biol. Rhythms 7, 287-299.

Chadwick, C. S. (1941). Identity of prolactin with water drive factor in Triturus viridescens. Proc. Soc. Exp. Biol. Med. 45, 335-337.

Cockrem, J. F., and Follett, B. K. (1985). Circadian rhythm of melatonin in the pineal gland of the Japanese quail (Coturnix coturnix japonica). J. Endocrinol. 107, 317-324.

Compagnone, N. A., Bulfone, A., (1995). Steroidogenic enzyme P450c17 is expressed in the embryonic central nervous system. Endocrinology 136, 5212-5223.

Compagnone, N. A., and Mellon, S. H. (2000). Neurosteroids: biosynthesis and function of these novel neuromodulators. Front. Neuroendocrinol. 21, 1-56.

Corpéchot, C., Robel, P., Axelson, M., Sjövall, J., and Baulieu, E.-E. (1981). Characterization and measurement of dehydroepiandrosterone sulfate in rat brain. Proc. Natl. Acad. Sci. U.S.A. 78, 4704-4707.

Corpéchot, C., Synguelakis, M., Talha, S., Axelson, M., Sjövall, J., Vihko, R., Baulieu, E. -E., and Robel, P. (1983). Pregnenolone and its sulfate ester in rat brain. Brain Res. 270, 119-125.

De Vito, W. J. (1988). Distribution of immunoreactive prolactin in the male and female rat brain: effects of hypophysectomy and intraventricular Rubenstein, J. L., and Mellon, S. H.

\section{ACKNOWLEDGMENTS}

This work was supported by Grants-in-Aid for Scientific Research from the Ministry of Education, Science and Culture, Japan (18107002, 22132004, and 22227002 to Kazuyoshi Tsutsui).

administration of colchicines Neuroendocrinology 47, 284-289.

Dent, L. N. (1975). Integumentary effects of prolactin in the lower vertebrates. Am. Zool. 15, 923-935.

Doostzadeh, J., and Morfin, R. (1997). Effects of cytochrome P450 inhibitors and of steroid hormones on the formation of 7-hydroxylated metabolites of pregnenolone in mouse brain microsomes. J. Endocrinol. 155, 343-350.

Do-Rego, J. L., Seong, J. Y., Burel, D. Leprince, J., Luu-The, V., Tsutsui, K., Tonon, M.-C., Pelletier, G., and Vaudry, H. (2009a). Neurosteroid biosynthesis: enzymatic pathways and neuroendocrine regulation by neurotransmitters and neuropeptides. Front Neuroendocrinol. 30, 259-301.

Do-Rego, J. L., Seong, J. Y., Luu-The, V. Tsutsui, K., Pelletier, G., Tonon, M.-C., and Vaudry, H. (2009b). Steroid biosynthesis within the frog brain: a model of neuroendocrine regulation. Ann. N. Y. Acad. Sci. 1163, 83-92.

Do-Rego, J. L., Tremblay, Y., Luu-The, V., Repello, E., Vallarino, M., Belanger, A., Pelletier, G., and Vaudry, $\mathrm{H}$. (2007). Immunocytochemical localization and biological activity of the steroidogenic enzyme cytochrome P450 17 $\alpha$-hydroxylase/C17, 20-lyase $\left(\mathrm{P} 450_{\mathrm{C} 17}\right)$ in the frog brain and pituitary. J. Neurochem. 100, 251-268.

Dupont, E., Simard, J., Luu-The, V., Labrie, F., and Pelletier, G. (1994). Localization of $3 \beta$-hydroxysteroid dehydrogenase in rat brain as studied by in situ hybridization. Mol. Cell. Neurosci. 5, 119-123.

Emanuele, N. V., Jurgens, J. K., Halloran, M. M., Tentler, J. J., Lawrence, A. M., and Kelley, M. R. (1992). The rat prolactin gene is expressed in brain tissue: detection of normal and alternative spliced prolactin messenger RNA. Mol. Endocrinol. 6, 35-42.

Freking, F., Nazairians, T., and Schlinger, B. A. (2000). The expression of the sex steroid-synthesizing enzymes CYP11A1, 3ß-HSD, CYP17, and CYP 19 in gonads and adrenals of adult and developing zebra finches. Gen. Comp. Endocrinol. 119, 140-151.

Fuxe, K., Hokfelt, T., Eneroth, P. Gustafsson, J. A., and Skett, P. (1977). Prolactin-like immunoreactivity: localization in nerve terminals of rat hypothalamus. Science 196, 899-900.

Giorgio, M., Giacoma, C., Vellano, C., and Mazzi, V. (1982). Prolactin and sexual behavior in the crested newt (Triturus cristatus carnifex Laur). Gen. Comp. Endocrinol. 47, 139-147.

Govek, E. K., and Swann. J. M. (2007). Stereological sex difference during development of the magnocelluar subdivision of the medial preoptic nucleus (MPN mag). Brain Res. 1145 , 90-96.

Govek, E. K., Wang, J., and Swann, J. M. (2003). Sex differences in the magnocellular subdivision of the medial preoptic nucleus in Syrian hamsters. Neuroscience 116, 593-598.

Guennoun, R., Fiddes, R. J., Gouézou, M., Lombès, M., and Baulieu, E.-E. (1995) A key enzyme in the biosynthesis of neurosteroids, $3 \beta$-hydroxysteroid dehydrogenase $/ \Delta^{5}-\Delta^{4}$-isomerase (3ß-HSD), is expressed in rat brain. Brain Res. Mol. Brain Res. 30, 287-300.

Hara, E., Kubikova, L., Hessler, N. A., and Jarvis, E. D. (2007). Role of the midbrain dopaminergic system in modulation of vocal brain activation by social context. Eur. J. Neurosci. 25, 3406-3416.

Haraguchi, S., Koyama, T., Hasunuma, I., Vaudry, H., and Tsutsui, K. (2010). Prolactin increases the synthesis of $7 \alpha$-hydroxypregnenolone, a key factor for induction of locomotor activity, in breeding male newts. Endocrinology 151, 2211-2222.

Haraguchi, S., Matsunaga, M., Koyama, T., Do Rego, J. L., and Tsutsui, K. (2009). Seasonal changes in the synthesis of the neurosteroid $7 \alpha$-hydroxypregnenolone stimulating locomotor activity in newts. Ann. N. Y. Acad. Sci. 1163, 410-413.

Hasunuma, I., Sakai, T., Nakada, T., Toyoda, F., Namiki, H., and Kikuyama, S. (2007). Molecular cloning of three types of arginine vasotocin receptor in the newt, Cynops pyrrhogaster. Gen. Comp. Endocrinol. 151, 252-258.

Hasunuma, I., Toyoda, F., Yamamoto, K., Yamashita, M., and Kikuyama, S. (2005). Localization of prolactin receptor in the newt brain. Cell Tissue Res. 320, 477-485.

Hau, M., and Gwinner, E. (1994). Melatonin facilitates synchronization of sparrow circadian rhythms to light. J. Comp. Physiol. A 175, 343-347.

Hu, Z. Y., Bourreau, E., Jung-Testas, I., Robel, P., and Baulieu, E.-E. (1987). Neurosteroids: oligodendrocyte mitochondria convert cholesterol to pregnenolone. Proc. Natl. Acad. Sci. U.S.A. 84, 8215-8219. 
Inai, Y., Nagai, K., Ukena, K., Oishi, T., and Tsutsui, K. (2003). Seasonal changes in neurosteroids in the urodele brain and environmental factors inducing their changes. Brain Res. 959, 214-225.

Iwahashi, K., Ozaki, H. S., Tsubaki, M., Ohnishi, J., Takeuchi, Y., and Ichikawa, Y. (1990). Studies of the immunohistochemical and biochemical localization of the cytochrome P-450scc-linked monooxygenase system in the adult rat brain. Biochim. Biophys. Acta. 1035, 182-189.

Iwata, T., Toyoda, F., Yamamoto, K., and Kikuyama, S. (2000). Hormonal control of urodele reproductive behavior. Comp. Biochem. Physiol. B, Biochem. Mol. Biol. 126, 221-229.

Jo, D. H., Abdallah, M.A., Young, J., Baulieu, E.-E.,and Robel,P.(1989).Pregnenolone, dehydroepiandrosterone, and their sulfate and fatty acid esters in the rat brain. Steroids 54, 287-297.

John, T. M., Itoh, S., and George, J. C. (1978). On the role of the pineal in thermoregulation in the pigeon. Horm. Res. 9, 41-56.

Jung-Testas, I., Hu, Z. Y., Baulieu, E.-E., and Robel, P. (1989). Neurosteroids:biosynthesis of pregnenolone and progesterone in primary cultures of rat glial cells. Endocrinology 125, 2083-2091.

Kabbadj, K., El-Etr, M., Baulieu, E.-E., and Robel,P. (1993). Pregnenolone metabolism in rodent embryonic neurons and astrocytes. Glia 7, 170-175.

Kikuyama, S., Hasunuma, I., Toyoda, F., Haraguchi, S., and Tsutsui, K. (2009). Hormone-mediated reproductive behavior in the red-bellied newt. Ann. N. Y. Acad. Sci. 1163, 179-186,

Kikuyama, S., Nakano, R., and Yasumasu, I. (1975). Synergistic action of prolactin and androgen on the cloacal glands of the newt. Comp. Biochem. Physiol. A Comp. Physiol. 51, 823-826.

Kikuyama, S., Toyoda, F., Ohmiya, Y., Matsuda, K., Tanaka, S., and Hayashi, H. (1995). Sodefrin: a female-attracting peptide pheromone in newt cloacal glands. Science 267, 1643-1645.

Kohchi, C., Ukena, K., and Tsutsui, K. (1998). Age- and region-specific expressions of the messenger RNAs encoding for steroidogenic enzymes P450scc, $\mathrm{P} 450 \mathrm{c} 17$ and 3ß-HSD in the postnatal rat brain. Brain Res. 801, 233-238.

Kumar, V., and Follett, B. K. (1993). The circadian nature of melatonin secretion in Japanese quail (Coturnix coturnix japonica). J. Pineal Res. 14, 192-200.

Lambert, J. J., Belelli, D., Hill-Venning, C., and Peters, J. A. (1995). Neurosteroids and GABA receptor function. Trends Pharmacol. Sci. 16, 295-303.

Lanthier, A., and Patwardhan, V. V. (1986). Sex steroids and 5-en-3 $\beta$ - hydroxysteroids in specific regions of the human brain and cranial nerves. J. Steroid Biochem. 25, 445-449.

Laviolette, S. R., and van der Kooy, D. (2001). GABA receptors in the ventral tegmental area control bidirectional reward signalling between dopaminergic and non-dopaminergic neural motivational systems. Eur. J. Neurosci. 13, 1009-1015.

Le Goascogne, C., Robel, P., Gouézou, M., Sananès, N., Baulieu, E.-E., and Waterman, M. (1987). Neurosteroids: cytochrome P-450scc in rat brain. Science 237, 1212-1215.

Lea, R. W., Clark, J. A., and Tsutsui, K. (2001). Changes in central steroid receptor expression, steroid synthesis and dopaminergic activity related to the reproductive cycle of the ring dove (review). Microsc. Res. Tech. 55, 12-26.

Levens, N., Green, T. A., Akins, C. K., and Bardo, M. T. (2000). Dopamine D2-like receptor binding in the brain of male Japanese quail (Coturnix japonica). Neurosci. Lett. 22, 77-80.

Massa, R., and Sharp, P. J. (1981). Conversion of testosterone to $5 \beta$-reduced metabolites in the neuroendocrine tissues of the maturing cockerel. J. Endocrinol. 88, 263-269.

Mathur, C., Prasad, V.V., Raju, V.S., Welch, M., and Lieberman, S. (1993). Steroids and their conjugates in the mammalian brain. Proc. Natl. Acad. Sci. U.S.A. 90, 85-88.

Matsuda, K., Tanaka, S., Yamamoto, K. and Kikuyama, S. (1990). Annual changes of plasma prolactin levels in the newt, Cynops pyrrhogaster. Zool. Sci. 7, 1143 .

Matsumoto, A., Arai, Y., Kouki, T., and Kikuyama, S. (1995). Comparison of Mauthner cell size in sexually developed and undeveloped male red-bellied newts. J. Neurobiol. 28, 126-132.

Matsunaga, M., Ukena, K., Baulieu, E.-E., and Tsutsui, K. (2004). $7 \alpha$-Hydroxypregnenolone acts as a neuronal activator to stimulate locomotor activity of breeding newts by means of the dopaminergic system. Proc. Natl. Acad. Sci. U.S.A. 101, 17282-17287.

Matsunaga, M., Ukena, K., and Tsutsui, K. (2001). Expression and localization of the cytochrome P450 17 $\alpha$ hydroxylase/c17,20-lyase in the avian brain. Brain Res. 899, 112-122.

Matsunaga, M., Ukena, K., and Tsutsui, K. (2002). Androgen biosynthesis in the quail brain. Brain Res. 948, 180-185.

Mellon, S. H., and Deschepper, C. F. (1993). Neurosteroid biosynthesis: genes for adrenal steroidogenic enzymes are expressed in the brain. Brain Res. 629, 283-292.
Mellon, S. H., and Vaudry, H. (2001). Biosynthesis of neurosteroids and regulation of their synthesis. Int. Rev. Neurobiol. 46, 33-78.

Mensah-Nyagan, A. G., Do-Rego, J. L., Beaujean, D., Luu-The, V., Pelletier, G., and Vaudry, H. (1999). Neurosteroids: expression of steroidogenic enzymes and regulation of steroid biosynthesis in the central nervous system (review) Pharmacol. Rev. 51, 63-81.

Mensah-Nyagan, A. G., Do-Rego, J. L. Feuilloley, M., Marcual, A., Lange, C., Pelletier, G., and Vaudry, H. (1996a). In vivo and in vitro evidence for the biosynthesis of testosterone in the telencephalon of the female frog. $J$. Neurochem. 67, 413-422.

Mensah-Nyagan, A. G., Feuilloley, M., Do-Rego, J. L., Marcual, A., Lange, C., Tonon, M. C., Pelletier, G., and Vaudry, H. (1996b). Localization of $17 \beta$-hydroxysteroid dehydrogenase and characterization of testosterone in the brain of the male frog. Proc. Natl. Acad. Sci. U.S.A. 93, 1423-1428.

Mensah-Nyagan, A. G., Feuilloley, M., Dupont,E.,Do-Rego,J.L.,Leboulenger, F., Pelletier, G., and Vaudry, H. (1994). Immunocytochemical localization and biological activity of $3 \beta$-hydroxysteroid dehydrogenase in the central nervous system of the frog. J. Neurosci. 14, 7306-7318.

Mezey, S., and Csillag, A. (2002). Selective striatal connections of midbrain dopaminergic nuclei in the chick (Gallus domesticus). Cell Tissue Res. 308, 35-46.

Mosconi, G., Yamamoto, K., Kikuyama, S., Carnevali, O., Mancuso, A., and Vellano, C. (1994). Seasonal changes of plasma prolactin concentration in the reproduction of the crested newt (Triturus carnifex Laur). Gen. Comp. Endocrinol. 95, 342-349.

Murakami, N., Kawano, T., Nakahara, K., Nasu, T., and Shiota, K. (2001). Effect of melatonin on circadian rhythm, locomotor activity and body temperature in the intact house sparrow, Japanese quail and owl. Brain Res. 889, 220-224.

Nakahara, K., Kawano, T., Shiota, K., and Murakami, N. (2003). Effects of microinjection of melatonin into various brain regions of Japanese quail on locomotor activity and body temperature. Neurosci. Lett. 345, 117-120.

Oliver, C., Mical, R. S., and Porter, J. C. (1977). Hypothalamic-pituitary vasculature: evidence for retrograde blood flow in the pituitary stalk. Endocrinology 101, 598-604.

Papadopoulos, V., Guarneri, P., Krueger, K. E., Guidotti, A., and Costa, E. (1992). Pregnenolone biosynthesis in C6-2B glioma cell mitochondria: regulation by a mitochondrial diazepam binding inhibitor receptor. Proc. Natl. Acad. Sci. U.S.A. 89, 5113-5117.

Paul, S. M., and Purdy, R. H. (1992). Neuroactive steroids. FASEB J. 6, 2311-2322.

Porter,J.C., Barnea, A., Cramer, O.M., and Parker, C. R. Jr. (1978). Hypothalamic peptide and catecholamine secretion: roles for portal and retrograde blood flow in the pituitary stalk in the release of hypothalamic dopamine and pituitary prolactin and LH. Clin. Obstet. Gynaecol. 5, 271-282.

Powers, J. B., Newman, S. W., and Bergondy, M. L. (1987). MPOA and BNST lesions in male Syrian hamsters: differential effects on copulatory and chemoinvestigatory behaviors. Behav. Brain Res. 23, 181-195.

Robel,P., and Baulieu,E.-E.(1985).Neurosteroids, $3 \beta$-hydroxy- $\Delta 5$-derivatives in the rodent brain. Neurochem. Int. 7 , 953-958.

Robel, P., Bourreau, E., Corpéchot, C. Dang, D. C., Halberg, F., Clarke, C., Haug, M., Schlegel, M. L., Synguelakis, M., Vourch, C., et al. (1987). Neurosteroids: $3 \beta$-hydroxy- $\Delta 5$-derivatives in rat and monkey brain. J. Steroid Biochem. 27, 649-655.

Robel,P.,Corpéchot, C., Clarke,C., Groyer, A., Synguelakis, M., Vourc'h, C., and Baulieu,E.-E. (1986). "Neuro-steroids: $3 \beta$-hydroxy- $\Delta 5$-derivatives in the rat brain," in Neuroendocrine Molecular Biology, eds G. Fink, A. J. Harmar, and K. W. McKerns (New York: Plenum Press), 367-377.

Rougé-Pont, F., Mayo, W., Marinelli, M., Gingras, M., Moal, M. L., and Piazza, P. V. (2002). The neurosteroid allopregnanolone increases dopamine release and dopaminergic response to morphine in the rat nucleus accumbens. Eur. J. Neurosci. 16, 169-173.

Sakamoto, H., Ukena, K., and Tsutsui, K. (2001). Activity and localization of $3 \beta$-hydroxysteroid dehydrogenase/ $\Delta^{5}$ $\Delta^{4}$-isomerase in the zebrafish central nervous system. J. Comp. Neurol. 439, 291-305.

Sanberg, P. R. (1983). Dopaminergic and cholinergic influences on motor behavior in chickens. J. Comp. Psychol. 97, 59-68.

Sanne, J. L., and Krueger, K. E. (1995). Expression of cytochrome P450 side-chain cleavage enzyme and $3 \beta$-hydroxysteroid dehydrogenase in the rat central nervous system: a study by polymerase chain reaction and in situ hybridization. J. Neurochem. 65 , 528-536.

Saper, C. B., Lu, J.,Chou, T.C., and Gooley, J. (2005). The hypothalamic integrator for circadian rhythms. Trends Neurosci. $28,152-157$.

Schlinger, B. A., and Callard, G. V. (1987). A comparison of aromatase, $5 \alpha$, and 
$5 \beta$-reductase activities in the brain and pituitary of male and female quail (Coturnix coturnix japonica). J. Exp. Zool. 242, 171-180.

Schlinger, B. A., and Callard, G. V. (1989a). Aromatase activity in quail brain: correlation with aggressiveness. Endocrinology 124, 437-443.

Schlinger, B. A., and Callard, G.V. (1989b). Localization of aromatase in synaptosomal and microsomal subfractions of quail (Coturnix coturnix japonica) brain. Neuroendocrinology 49, 434-441.

Schlinger, B. A., and Callard, G. V. (1991). "Brain-steroid interactions and the control of aggressive behavior in birds," in Neuroendocrine Perspectives, eds R. M. MacLeod and E. Muller (New York: Springer-Verlag), $1-43$.

Schlinger, B. A., Lane, N. I., Grisham, W., and Thompson, L. (1999). Androgen synthesis in a songbird: a study of cyp17 (17 $\alpha$-hydroxylase/c17,20-lyase) activity in the zebra finch. Gen. Comp. Endocrinol. 113, 46-58.

Sharp, T.,Zetterström, T.,Ljungberg,T., and Ungerstedt, U. (1987).A direct comparison of amphetamine-induced behaviours and regional brain dopamine release in the rat using intracerebral dialysis. Brain Res. 401, 322-330.

Soma, K. K., Alday, N. A., Hau, M., and Schlinger, B. A. (2004). Dehydroepiandrosterone metabolism by $3 \beta$-hydroxysteroid dehydrogenase $/ \Delta^{5}-\Delta^{4}$-isomerase in adult zebra finch brain: sex difference and rapid effect of stress. Endocrinology 145, 1668-1677.

Strömstedt, M., and Waterman, M. R. (1995). Messenger RNAs encoding steroidogenic enzymes are expressed in rodent brain. Brain Res. Mol. Brain Res. 34, 75-88.

Takase, M., Haraguchi, S., Hasunuma, I., Kikuyama, S., and Tsutsui, K. (2010). Expression of cytochrome P450 sidechain cleavage enzyme mRNA in the brain of the Red-bellied newt Cynops pyrrhogaster. Gen. Comp. Endocrinol. doi: 10.1016/j.ygcen.2010.10.019. [Epub ahead of print].

Takase, M., Ukena, K., and Tsutsui, K. (2002). Expression and localization of cytochromeP45011 $\beta$, aldo mRNAin the frog brain. Brain Res. 950, 288-296.

Takase, M., Ukena, K., Yamazaki, T., Kominami, S., and Tsutsui, K. (1999). Pregnenolone, pregnenolone sulfate and cytochrome P450 side-chain cleavage enzyme in the amphibian brain and their seasonal changes. Endocrinology 140, 1936-1944.

Tam, H., and Schlinger, B. A. (2007). Activities of $3 \beta$-HSD and aromatase in slices of developing and adult zebra finch brain. Gen. Comp. Endocrinol. 150, 26-33.
Toyoda, F., Hasunuma, I., Yamamoto, K., Yamashita, M., and Kikuyama, S. (2005). Prolactin acts centrally to enhance newt courtship behavior. Gen. Comp. Endocrinol. 141, 172-177.

Toyoda, F., Ito, M., Tanaka, S., and Kikuyama, S. (1993). Hormonal induction of male courtship behavior in the Japanese newt, Cynops pyrrhogaster. Horm. Behav. 27, 511-522.

Toyoda, F., Yamamoto, K., Ito, Y., Tanaka, S., Yamashita, M., and Kikuyama, S. (2003). Involvement of arginine vasotocin in reproductive events in the male newt Cynops pyrrhogaster. Horm. Behav. 44, 346-353.

Tsutsui, Y. (1931). Notes on the behavior of the common Japanese newt, Diemyctylus pyrrhogaster BOIE. I. Breeding habit. Mem. Coll. Sci. Kyoto Imp. Univ. Ser. B 7, 159-179.

Tsutsui, K., Haraguchi, S., Inoue, K., Miyabara, H., Suzuki, S., Ogura, Y., Koyama, T., Matsunaga, M., and Vaudry, H. (2009a). Identification, biosynthesis, and function of $7 \alpha$-hydroxypregnenolone, a new key neurosteroid controlling locomotor activity, in nonmammalian vertebrates. Ann. N. Y. Acad. Sci. 1163, 308-315.

Tsutsui, K., Inoue, K., Miyabara, H., Suzuki, S., Ogura, Y., Tobari, Y., and Haraguchi, S. (2009b). Discovery of a novel avian neurosteroid, $7 \alpha$-hydroxypregnenolone, and its role in the regulation of the diurnal rhythm of locomotor activity in Japanese quail. Gen. Comp. Endocrinol. 163, 117-122.

Tsutsui, K., Haraguchi, S., Matsunaga, M., Koyama, T., Do-Rego, J. L., and Vaudry, H. (2010). Identification of $7 \alpha$-hydroxypregnenolone, a novel bioactive amphibian neurosteroid stimulating locomotor activity, and its physiological roles in the regulation of locomotion. Gen. Comp. Endocrinol. $168,275-279$.

Tsutsui, K., Inoue, K., Miyabara, H., Suzuki, S., Ogura, Y., and Haraguchi, S. (2008). $7 \alpha$-Hydroxypregnenolone mediates melatonin action underlying diurnal locomotor rhythms. J. Neurosci. 28, 2158-2167.

Tsutsui, K., Matsunaga, M., Miyabara, H., and Ukena, K. (2006). Review: neurosteroid biosynthesis in the quail brain. J. Exp. Zool. 305A, 733-742.

Tsutsui, K., Matsunaga, M., and Ukena, K. (2003). Review: biosynthesis and biological actions of neurosteroids in the avian brain. Avian Poultry Biol. Rev. 14, 63-78.

Tsutsui, K., and Mellon, S. H. (2006). Review: neurosteroids in the brain neuron: biosynthesis, action and medicinal impact on neurodegenerative disease. Central Nerv. Syst. Agents Med. Chem. 6, 73-82.
Tsutsui, K., and Schlinger, B. A. (2001). "Steroidogenesis in the Avian brain," in Avian Endocrinology, eds A. Dawson and C. M. Chaturvedi (New Delhi: Narosa Publishing House), 59-77.

Tsutsui, K., Ukena, K., Takase, M., Kohchi, C., and Lea, R.W. (1999). Review: neurosteroid biosynthesis in vertebrate brains. Comp. Biochem. Physiol. C Toxicol. Pharmacol. 124, 121-129.

Tsutsui, K., Ukena, K., Usui, M., Sakamoto, H., and Takase, M. (2000). Novel brain function: biosynthesis and actions of neurosteroids in neurons (review). Neurosci. Res. 36, 261-273.

Tsutsui, K., and Yamazaki, T. (1995). Avian neurosteroids. I. Pregnenolone biosynthesis in the quail brain. Brain Res. 678, 1-9.

Tsutsui, K., Yamazaki, T., Usui, M., Furukawa, Y., Ukena, K., Kohchi, C., and Kominami, S. (1997). "P450scc activity in the brain," in Perspectives in Avian Endocrinology, eds S. Harvey and R. J. Etches (Bristol: Journal of Endocrinol Ltd), 427-436.

Ukena, K., Honda, Y., Inai, Y., Kohchi, C., Lea, R. W., and Tsutsui, K. (1999). Expression and activity of $3 \beta$-hydroxysteroid dehydrogenase $/ \Delta^{5}$ $\Delta^{4}$-isomerase in different regions of the avian brain. Brain Res. 818, 536-542.

Ukena, K., Honda, Y., Lea, R. W., and Tsutsui, K. (2001). Developmental changes in progesterone biosynthesis and metabolism in the quail brain Brain Res. 898, 190-194.

Ukena, K., Kohchi, C., and Tsutsui, K. (1999). Expression and activity of $3 \beta$-hydroxysteroid dehydrogenase $/ \Delta^{5}$ $\Delta^{4}$-isomerase in the rat Purkinje neuron during neonatal life. Endocrinology 140, 805-813.

Ukena, K., Usui, M., Kohchi,C., and Tsutsui, K. (1998). Cytochrome P450 sidechain cleavage enzyme in the cerebellar Purkinjeneuron and its neonatal change in rats. Endocrinology 139, 137-147.

Usui, M., Yamazaki, T., Kominami, S., and Tsutsui, K. (1995). Avian neurosteroids. II. Localization of a cytochrome P450scc-like substance in the quail brain. Brain Res. 678, 10-20.

Vanson, A., Arnold, A. P., and Schlinger, B. A. (1996).33-Hydroxysteroid dehydrogenase/isomerase and aromatase activity in primary cultures of developing zebra finch telencephalon: dehydroepiandrosterone as substrate for synthesis of androstenedione and estrogens. Gen. Comp. Endocrinol. 102, 342-350.

Wada, M. (1979). Photoperiodic control of $\mathrm{LH}$ secretion in Japanese quail with special reference to the photoinducible phase. Gen. Comp. Endocrinol. 39 , 141-149.

Walsh, R. G., Slaby, F. J., and Posner, B. I. (1987). A receptor-mediated mechanism for the transport of prolactin from blood to cerebrospinal fluid. Endocrinology 120, 1846-1850.

Warren, W. S., and Cassone, V. M. (1995). The pineal gland: photoreception and coupling of behavioral, metabolic, and cardiovascular circadian outputs. J. Biol. Rhythms 10, 64-79.

Weidenfeld, J., Siegel, R. A., and Chowers, I. (1980). In vitro conversion of pregnenolone to progesterone by discrete brain areas of the male rat. J. Steroid Biochem. 13, 961-963.

Weill-Engerer, S., David, J. P., Sazdovitch, V., Liere, P., Schumacher, M., Delacourte, A., Baulieu, E.-E., and Akwa, Y. (2003). In vitro metabolism of dehydroepiandrosterone (DHEA) to $7 \alpha$-hydroxy-DHEA and $\Delta 5$-androstene-3 $\beta, 17 \beta$-diol in specific regions of the aging brain from Alzheimer's and non-demented patients. Brain Res. 969, 117-125.

Wieland, S., Belluzzi, J. D., Stein, L., and Lan, N. C. (1995). Comparative behavioral characterization of the neuroactive steroids 3 alpha- $\mathrm{OH}, 5$ alpha-pregnan-20-one and 3 alpha$\mathrm{OH}, 5$ beta-pregnan-20-one in rodents. Psychopharmacology 118, 65-71.

Wilson, W. O. (1972). A review of the physiology of Coturnix (Japanese quail). Worlds Poult. Sci. J. 28, 413-429.

Yau, J. L., Rasmuson, S., Andrew, R., Graham, M., Noble, J., Olsson, T., Fuchs, E., Lathe, R., and Seckl, J. R. (2003). Dehydroepiandrosterone 7-hydroxylase CYP7B: predominant expression in primate hippocampus and reduced expression in Alzheimer's disease. Neuroscience 121, 307-314.

Conflict of Interest Statement: The authors declare that the research was conducted in the absence of any commercial or financial relationships that could be construed as a potential conflict of interest.

Received: 21 October 2010; paper pending published: 05 December 2010; accepted: 10 December 2010; published online: 24 December 2010.

Citation: Tsutsui K, Haraguchi S, Matsunaga M, Inoue K and Vaudry $H$ (2010) 7 $\alpha$-Hydroxypregnenolone, a new key regulator of locomotor activity of vertebrates: identification, mode of action, and functional significance. Front. Endocrin. 1:9. doi: 10.3389/fendo.2010.00009

This article was submitted to Frontiers in Neuroendocrine Science, a specialty of Frontiers in Endocrinology.

Copyright () 2010 Tsutsui, Haraguchi, Matsunaga, Inoue and Vaudry. This is an open-access article subject to an exclusive license agreement between the authors and the Frontiers Research Foundation, which permits unrestricted use, distribution, and reproduction in any medium, provided the original authors and source are credited. 